\title{
Motoneurons Secrete Angiogenin to Induce RNA Cleavage in Astroglia
}

\author{
Alexandra Skorupa, ${ }^{1,2 \star}$ Matthew A. King, ${ }^{1 \star}$ Isabela M. Aparicio, ${ }^{1}$ Heiko Dussmann, ${ }^{1}$ Karen Coughlan, ${ }^{1}$ Bridget Breen, ${ }^{1}$ \\ Dairin Kieran, ${ }^{1}$ Caoimhin G. Concannon, ${ }^{1}$ Philippe Marin, ${ }^{2}$ and Jochen H. M. Prehn ${ }^{1}$ \\ ${ }^{1}$ Department of Physiology and Medical Physics, Centre for the Study of Neurological Disorders, Royal College of Surgeons in Ireland, Dublin 2, Ireland, and \\ 2Département de Neurobiologie, Institut de Génomique Fonctionnelle, INSERMU661, Centre National de la Recherche Scientifique (CNRS) UMR 5203, \\ Universités de Montpellier, 34094 Montpellier, France
}

Amyotrophic lateral sclerosis (ALS) is an incurable neurodegenerative disorder affecting motoneurons. Mutations in angiogenin, encoding a member of the pancreatic RNase A superfamily, segregate with ALS. We previously demonstrated that angiogenin administration shows promise as a neuroprotective therapeutic in studies using transgenic ALS mice and primary motoneuron cultures. Its mechanism of action and target cells in the spinal cord, however, are largely unknown. Using mixed motoneuron cultures, motoneuron-like NSC34 cells, and primary astroglia cultures as model systems, we here demonstrate that angiogenin is a neuronally secreted factor that is endocytosed by astroglia and mediates neuroprotection in paracrine. We show that wild-type angiogenin acts unidirectionally to induce RNA cleavage in astroglia, while the ALS-associated K40I mutant is also secreted and endocytosed, but fails to induce RNA cleavage. Angiogenin uptake into astroglia requires heparan sulfate proteoglycans, and engages clathrin-mediated endocytosis. We show that this uptake mechanism exists for mouse and human angiogenin, and delivers a functional RNase output. Moreover, we identify syndecan 4 as the angiogenin receptor mediating the selective uptake of angiogenin into astroglia. Our data provide new insights into the paracrine activities of angiogenin in the nervous system, and further highlight the critical role of non-neuronal cells in the pathogenesis of ALS.

\section{Introduction}

Amyotrophic lateral sclerosis (ALS) is a late-onset and fatal neurodegenerative disease. Approximately $10 \%$ of ALS cases are dominantly inherited. The most common genetic determinant of ALS is disruption to the $\mathrm{Cu} / \mathrm{Zn}$ superoxide dismutase 1 (SOD1) locus, at which a series of substitution mutations have been catalogued, that can recapitulate the major disease features in transgenic animals (Rosen et al., 1993; Gurney et al., 1994). A curious feature determining the disease state in SOD1 transgenic mice is the influence of intercellular signaling pathways on disease onset and progression. This feature was highlighted initially by reports that disease penetrance in transgenic mice required the expression of mutant SOD1 (mSOD1) in a number of tissues, as opposed to either motoneurons or astroglia alone (Gurney et al., 1994; Gong et al., 2000; Pramatarova et al., 2001). By using mSOD1 chimeric animals, it was also found that a minority of wild-type (WT) astroglia are

\footnotetext{
Received Dec. 21, 2011; revised Feb. 10, 2012; accepted Feb. 13, 2012.

Author contributions: D.K., P.M., and J.H.M. P. designed research; A.S., M.A.K., I.M.A., H.D., K.C., B.B., and C.G.C. performed research; I.M.A. and H.D. analyzed data; A.S. and M.A.K. wrote the paper.

This research was supported by a Co-Tutelle PhD studentship provided by the National Biophotonics and Imaging Platform Ireland (funded by the Irish Government's Programme for Research in Third Level Institutions, Cycle 4, National Development Plan 2007-2013'), and by grants from Enterprise Ireland (TD 20090107), Science Foundation Ireland (08/IN1/B1949), and the Fondation Thierry Latran (AAP2011/PREHN) to J.H.M.P. We thankSarah Cannon for technical assistance and Dr. Guo Fu Hu (Harvard Medical School.) for kindly providing anti-human angiogenin antiserum.

${ }^{*}$ A.S. and M.A.K contributed equally to this work.

Correspondence should be addressed to Prof. Jochen H. M. Prehn, Department of Physiology and Medical Physics, Royal College of Surgeons in Ireland, 123 St. Stephen's Green, Dublin 2, Ireland. E-mail: prehn@rcsi.ie.

DOI:10.1523/JNEUROSCI.6366-11.2012

Copyright $\odot 2012$ the authors $\quad 0270-6474 / 12 / 325024-15 \$ 15.00 / 0$
}

sufficiently protective to delay the onset of ALS within an mSOD1 majority background, by protecting mSOD1-expressing motoneurons from cell death (Clement et al., 2003). These investigations therefore support a pathogenesis in which mutant SOD1 disrupts autocrine/paracrine pathways, which under normal circumstances can provide robust neuroprotection when activated in astroglia alone. Moreover, mSOD1-expressing glia may contribute to motoneuron death by secreting factors selectively toxic to motoneurons (Raoul et al., 2002; Di Giorgio et al., 2007; Nagai et al., 2007; Yamanaka et al., 2008). It is therefore clear that mechanisms mediating motoneuron death can be subverted or exacerbated by astroglial functions and define paracrine interactions as critical regulators of the ALS disease state.

A candidate paracrine system recently linked with the development of ALS is the angiogenin signaling network (Greenway et al., 2006). Angiogenin is a secreted RNase of the pancreatic RNase A superfamily, showing rRNA and tRNA substrate cleavage, and defined by its potency to induce neovascularization (Fett et al., 1985; Shapiro et al., 1986; St Clair et al., 1987). Despite retaining only $10^{-5}$ - to $10^{-6}$-fold the activity of RNase A, the weak RNase activity of angiogenin is critical to its angiogenic activity (Shapiro and Vallee, 1989; Shapiro et al., 1989; Leland et al., 2002). The majority of mutations that segregate with ALS do not significantly alter the secondary structure or stability of the protein, but rather disrupt its RNase function or subcellular distribution (Moroianu and Riordan, 1994; Leland et al., 2002; Greenway et al., 2006; Crabtree et al., 2007).

We previously showed that angiogenin treatment extends the lifespan of transgenic ALS mice and is neuroprotective in vitro 
when applied to mixed primary motoneuron cultures (Kieran et al., 2008; Sebastià et al., 2009). The mechanism of action of angiogenin in the spinal cord as well as its receptor and target cells, however, remain largely undefined. Here, we demonstrate that angiogenin is a neuronally secreted protein that is endocytosed by astroglia and mediates neuroprotection in paracrine. We demonstrate that angiogenin targets astrocytes to induce RNA cleavage and define the uptake mechanisms and binding proteins involved in this process.

\section{Materials and Methods}

All experiments were performed under license from the Department of Health and Children (B100/3534), and following ethical approval by the Research Ethics Committee of the Royal College of Surgeons in Ireland.

Primary motoneuron and astrocyte cultures. Primary motoneuron cultures were established from E13 C57 mouse embryos of either sex (Camu and Henderson, 1992). Spinal cord ventral horns were dissected from individual embryos, and the ventral horn tissue was cut into $<1 \mathrm{~mm}$ pieces and incubated for 10 min in $0.025 \%$ trypsin in Ham F10 modified medium ( Invitrogen). The cells were then gently dissociated in complete medium containing $0.4 \%$ BSA and $0.1 \mathrm{mg} / \mathrm{ml}$ DNase I (Sigma). Cells were seeded at $5 \times 10^{4} / \mathrm{ml}$ and maintained at $37^{\circ} \mathrm{C}$ and $5 \% \mathrm{CO}_{2}$. Where stated, uridine/fluorodeoxyuridine $(20 \mu \mathrm{M})$ was added to motoneuron cultures from day 3 in vitro (DIV) to DIV 6 to inhibit glial proliferation.

Primary astrocyte cultures were prepared from P2 C57 Black 6 mouse pups of either sex. Cortices were dissected and the meninges removed before incubation in Minimum Essential Medium ( Invitrogen) containing $0.025 \%$ trypsin and $0.1 \mathrm{mg} / \mathrm{ml}$ DNase I for $15 \mathrm{~min}$ at $37^{\circ} \mathrm{C}$. The tissue was triturated three times in DMEM ( $4.5 \mathrm{~g} / \mathrm{L}$ glucose; Lonza) containing $0.1 \mathrm{mg} / \mathrm{ml}$ DNase I to dissociate cells. Astrocytes were plated in full DMEM containing $2 \mathrm{~mm}$ L-glutamine (Sigma), $100 \mathrm{U} / \mathrm{ml}$ penicillin/ streptomycin (Sigma), and 10\% (v/v) heat-inactivated fetal bovine serum (FBS; Sigma). All assays were performed on cell cultures after passage one containing $\sim 75 \%$ astrocytes.

Tissue culture. Motoneuronal NSC34 (Camu and Henderson, 1992) and MZ-294 (Hetschko et al., 2008) human astrocytoma cells were cultured in high-glucose (4.5 g/L) DMEM containing 10\% (v/v) FBS and 1\% penicillin/streptomycin. Brefeldin A (BFA; Sigma) was used from 0.1 to $10 \mathrm{M}$ as indicated and tunicamycin (Qbiogene) was used at $500 \mathrm{~nm}$. All experiments were repeated in triplicate.

Western blotting and trichloroacetic acid precipitation of conditioned medium. Cells were collected in SDS lysis buffer $(62.5 \mathrm{~mm}$ Tris- $\mathrm{HCl}, \mathrm{pH}$ $6.8,10 \%$ glycerin, $2 \%$ SDS) supplemented with protease inhibitor mixture and phosphatase inhibitors (Sigma). Protein content of cell lysates was determined using a bicinchoninic acid (BCA) protein determination kit (Pierce) and equal amounts of protein were diluted in Laemmli buffer and separated by electrophoresis on $6-15 \%$ polyacrylamide gels after boiling for $5 \mathrm{~min}$. Gels were transferred onto nitrocellulose membranes and blocked for $1 \mathrm{~h}$ in 5\% milk in TBS plus $0.5 \%$ Tween 20 (Sigma). Membranes were then incubated with primary antibodies overnight at $4^{\circ} \mathrm{C}$ on a roller mixer: Goat anti-angiogenin (1:1000; Merck PC317L), mouse anti- $\beta$-actin (1:2500; Sigma), mouse anti- $\alpha$-tubulin (1:2000; Sigma), rabbit anti-glial fibrillary acidic protein (GFAP; 1:1000; Sigma), rabbit anti-lamin A (1:500;Santa Cruz Biotechnology), rabbit anti-rab 5 (1:1000; Abcam), rabbit anti-green fluorescent protein (GFP; 1:1000; Abcam), and rabbit anti-syndecan 4 (1:1000; Abcam). After three washes the membrane was incubated with horseradish peroxidase-conjugated secondary antibody (1:5000; Jackson ImmunoResearch) for $1 \mathrm{~h}$ at room temperature. Finally, membranes were washed four times and incubated with enhanced chemiluminescence substrate (Millipore) for $1 \mathrm{~min}$ before image capture using an LAS 3000 Reader (Fujifilm).

Cell fractionation to separate nuclei and cytosolic components was performed as described previously (Engel et al., 2010).

Conditioned medium collected for Western blotting was first centrifuged for $5 \mathrm{~min}$ at $2000 \mathrm{rpm}$ to remove any floating cells, adjusted to $10 \%$ trichloroacetic acid and incubated on ice for $30 \mathrm{~min}$. Precipitated protein was collected by centrifugation at 14,000 rpm for $30 \mathrm{~min}$ and resuspended in $20 \mu \mathrm{l}$ of SDS-loading buffer and neutralized with $2 \mu \mathrm{l}$ of Tris base $(2.5 \mathrm{M})$. Protein content was determined by BCA assay before dilution in $6 \times$ loading buffer $(0.5 \mathrm{M}$ Tris- $\mathrm{HCl}, \mathrm{pH} 6.8,30 \%$ glycerol, $10 \%$ SDS, and $0.6 \mathrm{~m}$ dithiothreitol) and boiling for $5 \mathrm{~min}$.

Transient transfection and production of ang-conditioned medium. Plasmids expressing human WT or K40I angiogenin from a cytomegalovirus (CMV) promoter together with DsRed translated from an internal ribosome entry site (pIRES2-DsRed2 ANG WT or K40I) have been described previously (Sebastià et al., 2009). Empty pIRES-GFP plasmid was used for control transfections. Plasmids expressing turboGFP-tagged syndecan 4 under the control of the CMV promoter and shRNA vector expressing a syndecan 4-specific shRNA construct (sequence GGTTCT GGAGATCTGGATGACACGGAGGA) or a scrambled sequence under the control of the U6 promoter along with turboGFP under the CMV promoter (pGFP-V-RS) were purchased from Origene. The plasmid encoding GFP-tagged rAP180 C terminus was a kind gift from Dr. McMahon (Doherty and McMahon, 2009), and the GFP-tagged dominantnegative dynamin 1 construct was a kind gift from Dr. Marin (Damke et al., 1994).

NSC34 cells were seeded at a density of 150,000 cells per ml in 6-well plates and left to recover and reach $60 \%$ confluence $(24 \mathrm{~h})$. For each condition, $3 \mu \mathrm{g}$ of DNA was mixed with $6 \mu \mathrm{l}$ Lipofectamine 2000 (Invitrogen) for $20 \mathrm{~min}$ and incubated overnight. Following transfection, NSC34 cells were washed and culture medium was replaced with either full medium or Neurobasal medium (containing penicillin/streptomycin, L-glutamine, and FBS as stated) for generating conditioned medium.

Astrocytes were seeded at a density of $3 \times 10^{5}$ cells per well of a 24 -well plate on poly-L-ornithine-coated coverslips and transfected after $24 \mathrm{~h}$. Transfection was performed by mixing $1 \mu \mathrm{g}$ of DNA with $2 \mu \mathrm{l}$ of Lipofectamine 2000 per well for $20 \mathrm{~min}$. After $8 \mathrm{~h}$ of syndecan 4, rAP180 and $d n D y n$ overexpression, or $48 \mathrm{~h}$ for syndecan 4 gene silencing in antibioticfree medium, the medium was replaced with full medium until cell treatment with recombinant human angiogenin.

Paracrine RNA cleavage assay-RNA extraction and PAGE analysis. Conditioned medium containing secreted $A N G$ or $A N G$ variants was collected from NSC34 cells, centrifuged for $5 \mathrm{~min}$ at $2000 \mathrm{rpm}$ to remove any floating cells, and applied to sister NSC34 cell cultures or MZ-294 cells. A neutralizing angiogenin antibody (Merck PC317L) was used to inactivate endogenous angiogenin. Cells were incubated and conditioned for $1-3 \mathrm{~h}$ prior and total RNA was harvested using Trizol (Invitrogen). NSC34 cells were collected in $200 \mu \mathrm{l}$ of Trizol using the plunger from a $1 \mathrm{ml}$ syringe, whereas for primary motoneuron cultures in 24-well plates cells were collected in $50 \mu \mathrm{l}$ of Trizol per well. Trizol extracts were homogenized by trituration with a 200 pipette and centrifuged at 12,000 $\mathrm{rpm}$ for $10 \mathrm{~min}$ at $4^{\circ} \mathrm{C}$. The cleared homogenate was transferred to a fresh tube, adjusted to $20 \%$ chloroform (Sigma), and shaken for $15 \mathrm{~s}$. After a 3 min incubation at room temperature, the samples were centrifuged at $13,000 \mathrm{rpm}$ for $15 \mathrm{~min}\left(4^{\circ} \mathrm{C}\right)$ after which the aqueous (upper) phase was collected. DNA was removed by precipitation with isopropanol (adjusting to $10 \%$; Sigma) and centrifugation (13,000 rpm for $5 \mathrm{~min}$ ). RNA was precipitated by adjusting to $50 \%$ isopropanol and centrifuged for $15 \mathrm{~min}$ at $13,000 \mathrm{rpm}$. RNA pellets were washed with $75 \%$ ethanol and resolubilized in $11 \mu \mathrm{l}$ of DEPC-treated $\mathrm{H}_{2} \mathrm{O}$ for $10 \mathrm{~min}$ at $55^{\circ} \mathrm{C}$. RNA concentrations were quantified by measuring the absorption of $1 \mu \mathrm{l}$ of RNA solution at $\lambda=260 \mathrm{~nm}$ on a NanoDrop spectrophotometer. RNA was mixed with $2 \times$ loading buffer (90\% formamide, 11 mM EDTA, pH 8.0, and $0.2 \%$ Orange $\mathrm{G}$ ) and $3-5 \mu \mathrm{g}$ was separated by electrophoresis on $15 \%$ polyacrylamide TBE-UREA gels for $95 \mathrm{~min}$ at $200 \mathrm{~V}$ (Yamasaki et al., 2009). RNA was stained with SYBR Gold (Invitrogen) and visualized by transillumination within an LAS 3000 Reader (Fujifilm).

Immunocytochemistry. Immunocytochemistry was performed on NSC34, astrocyte, and motoneuron cultures seeded on poly-L-ornithinecoated coverslips in 24-well plates. Cells were washed in ice-cold PBS and fixed for $20 \mathrm{~min}$ in 4\% paraformaldehyde (PFA; Sigma-Aldrich) in PBS and sucrose at room temperature. After washing in PBS, the cells were blocked with $5 \%$ milk in PBS/0.1\% Triton X-100 for $1 \mathrm{~h}$ at room temperature. Coverslips were incubated with primary antibodies overnight at $4^{\circ} \mathrm{C}$ : mouse anti-SMI-32 (1:1000; Abcam), goat anti-angiogenin (1: 500; Merck PC317L), rabbit anti anti-GFAP (1:500; Sigma), rabbit anticlathrin heavy chain (1:1000; Abcam), or rabbit anti-syndecan 4 (1:100; 
Abcam). Coverslips were washed in PBS/Triton X-100 and PBS and incubated with secondary antibodies from Jackson ImmunoResearch for $1 \mathrm{~h}$ at room temperature: rhodamine red-conjugated anti-mouse IgG, 1:500; FITC-conjugated anti-rabbit IgG; and anti-goat IgG, 1:500. Coverslips were washed and mounted in Vectashield containing $4^{\prime}, 6$ diamidino-2-phenylindole (DAPI, Vector Laboratories) and visualized on a TE 2000-S epifluorescent microscope (Nikon). Colocalization analysis of angiogenin-containing vesicles with other vesicular markers was performed using an LSM 710 confocal microscope (Zeiss) with Zen 2009 software. Quantification of angiogenin uptake-positive cells was performed in a blinded fashion using AlphaEaseFC software (Alpha Innotech) by scoring those cells as positive that showed a bright, punctuate angiogenin staining and that were also positively stained with the respective marker (SMI-32 or GFAP). Cells with a lack of angiogenin staining or with diffuse angiogenin staining were scored as angiogenin uptakenegative cells. Cells were counted from at least six random fields of view per coverslip at 60-fold magnification; each condition was tested on two coverslips. Syndecan 4 gene silencing was quantified by immunofluorescence analysis and compared with cells transfected with the scrambled shRNA. The average intensity of the cellular syndecan 4 immunofluorescence after background subtraction was divided by the average intensity of GFP fluorescence to compensate for differences in transfection efficiency.

Angiogenin uptake and localization in vitro. Recombinant human angiogenin was purchased from R\&D Systems and used at $100-1000 \mathrm{ng} / \mathrm{ml}$ as indicated. Fluorescence and confocal images were captured using Nikon eclipse TE300 or Zeiss AxioImager Z1 microscopes and LSM 510, LSM 710, or LSM 780 (Zeiss) confocal microscopes, respectively. Cytochalasin D (CytoD) and phalloidin-TRIC were obtained from Sigma. Angiogenin-conditioned medium was prepared from motoneuron cultures treated with angiogenin for $6 \mathrm{~h}$, followed by an $18 \mathrm{~h}$ washout period.

Proximity ligation assay. Proximity ligation assay (PLA) was conducted on astrocytes seeded in 8-well chamber slides (IBIDI). Astrocytes were treated with angiogenin and fixed in $4 \%$ PFA. Staining with primary antibodies was performed similarly to conventional immunocytochemistry (mouse anti-angiogenin, 1:250; Abcam). Instead of using fluorescently labeled secondary antibodies, a proximity ligation approach was applied following manufacturer's instructions (Olink Bioscience). In brief, samples were incubated with secondary antibodies conjugated with DNA probes (minus and plus DNA probes). Probes were hybridized and ligated, followed by amplification of the DNA template in a rolling circle amplification reaction. Detection solution was added to identify amplified DNA. All reaction steps were performed in a humidity chamber at $37^{\circ} \mathrm{C}$. Signals were detected using both a TE $2000-\mathrm{S}$ epifluorescence microscope (Nikon) and an LSM 710 confocal microscope (Zeiss). Spots were quantified using the blob-finder software provided by Olink Biosciences on random 60-fold magnification epifluorescent images (settings, minimal nucleus size 100 pixels; cytoplasm size 100 pixels; blob size $3 \times$ 3 pixels) and counts were tested for statistical significance between three separate experiments using Student's $t$ test.

Manipulation of endocytosis. The salt concentration and osmolarity of Neurobasal were adjusted with $\mathrm{NaCl}, \mathrm{CaCl}_{2}$, and sucrose (all from Sigma) to correlate with the amount measured for DMEM (3000- 6400 $\mathrm{mg} / \mathrm{L} \mathrm{NaCl}, 200-264 \mathrm{mg} / \mathrm{L} \mathrm{CaCl}_{2}$, and 235-335 mosm). All endocytosis inhibitors were purchased from Sigma and used at the indicated concentrations and preincubation times: monodansylcadaverine (MDC; 0.2 $\mathrm{mM}, 1 \mathrm{~h}$ ), methyl- $\beta$-cyclodextrin ( $\mathrm{M} \beta \mathrm{CD} ; 0.24 \%, 1 \mathrm{~h})$, dynasore (40 or $160 \mu \mathrm{M}, 30 \mathrm{~min})$, heparinase I $(2.5 \mathrm{U} / \mathrm{ml}, 2 \mathrm{~h})$, heparin $(10 \mu \mathrm{g} / \mathrm{ml}, 2 \mathrm{~h})$, and CytoD $(1 \mu \mathrm{g} / \mathrm{ml}, 1 \mathrm{~h})$. The uptake of $1 \mu \mathrm{g} / \mathrm{ml}$ angiogenin was determined after $1 \mathrm{~h}$ treatment in Neurobasal medium containing L-glutamine and penicillin/streptomycin following cell fixation and immunofluorescence detection of angiogenin. For quantification, cells were counted from at least six random fields of view per coverslip at 60-fold magnification; each condition was tested on two coverslips. Values obtained from triplicate experiments were statistically tested using Student's $t$ test.

Motoneuron survival in vitro. Primary motoneuron cultures at DIV 7 were treated with AMPA (50 $\mu$; Tocris Cookson) and cotreated with human recombinant angiogenin protein $(100 \mathrm{ng} / \mathrm{ml}$ dissolved in sterile
PBS; R\&D systems), angiogenin- conditioned medium, or denatured angiogenin-conditioned medium for $24 \mathrm{~h}$. Viability of motoneuron cultures was assessed by reduction of 3-(4,5-dimethylthiazol-2-yl)-2,5diphenyltetrazolium bromide (MTT; Sigma). Motoneuron cultures were prepared in 96-well plates and treated as described above. MTT was dissolved in PBS ( $5 \mathrm{mg} / \mathrm{ml})$ and diluted 1:10 in culture medium, added to cells, and incubated for $4 \mathrm{~h}$ at $37^{\circ} \mathrm{C}$. The media was then replaced with isopropanol containing $0.04 \mathrm{~m}$ hydrochloric acid. Reduced MTT was quantified by absorption at $\lambda=570 \mathrm{~nm}$ using a plate reader (Tecan). All experiments were repeated in triplicate and compared statistically using Student's $t$ test. Direct assessment of motoneuron survival was determined by immunostaining for the motoneuron-specific marker, SMI-32 (Kieran et al., 2008). After treatment, cultures were incubated in trypan blue (Sigma) for 5 min, washed in PBS, and fixed with 4\% PFA. Cultures were then immunostained with antibodies to SMI-32 as described previously. Motoneuron death was quantified by counting only the SMI-32positive cells, with typical morphology (triangular shape and single, well defined axon), large bodies ( $>20 \mu \mathrm{m})$, and with intact axons and dendrites. Three nonoverlapping images per coverslip were captured at 40fold magnification and counted using AlphaEaseFC software.

Real-time qPCR. Total RNA was extracted using the RNeasy Mini Kit (Qiagen). First-strand cDNA synthesis was performed using $2 \mu \mathrm{g}$ of total RNA as a template and Moloney murine leukemia virus reverse transcriptase (Invitrogen) primed with $50 \mathrm{pmol}$ of random hexamers. Quantitative real-time PCR was performed using the LightCycler (Roche Diagnostics) and the QuantiTech SYBR Green PCR kit (Qiagen) as per manufacturers' protocols. Specific primers were designed using Primer3 software (http://frodo.wi.mit.edu/primer3). Sense and antisense primers used were as follows: $5^{\prime}$-CACAGATGGCCTTGATGTTG-3' 5' $^{\prime}$-CTCT GGCTCAGCATGACTCC-3', for murine angl and 5' -AGGTGTGATG GTGGGAATGG-3', and 5'-GGTTGGCCTTAGGGTTCAGG-3' for murine $\beta$-actin. The generation of specific PCR products was confirmed by melting curve analysis and gel electrophoresis. The data were analyzed using the LightCycler software 4.0 with all samples normalized to $\beta$-actin.

\section{Results}

\section{Astroglia, but not primary motoneurons,} endocytose angiogenin

Our previous reports established angiogenin as a neuroprotective factor for primary motoneurons (Kieran et al., 2008; Sebastià et al., 2009). To begin elucidating the mechanism of neuroprotection conferred by angiogenin we first investigated the subcellular localization and uptake of recombinant human angiogenin (rhAng) in mixed primary motoneuron cultures derived from the ventral horn. Consistent with our previous reports (Greenway et al., 2006), we found that under control conditions motoneurons, which stain for the neurofilament marker SMI-32, showed immunoreactivity for endogenous angiogenin when compared with non-neuronal cells (Fig. 1A). This result was quantitatively confirmed by evaluating ang1 mRNA expression in mixed murine motoneuron cultures versus primary astrocyte cultures by qRT-PCR (Fig. $1 B$ ), and is in accordance with previous published work showing the absence of angiogenin expression in non-neuronal cells during mouse embryonic development and neural development (Subramanian and Feng, 2007).

We next investigated rhAng uptake by immunocytochemistry from different developmental stages, from DIV 1 through to DIV 9, over a time course of $30 \mathrm{~min}$ to $24 \mathrm{~h}$. However, across these conditions, we could not detect any changes in the intensity or distribution of angiogenin immunofluorescence in SMI-32positive neurons by immunocytochemistry (Fig. 1C, top, compare 1 and $6 \mathrm{~h}$ uptake). In contrast, cells in the non-neuronal plane of the same primary mixed motoneuron cultures showed 

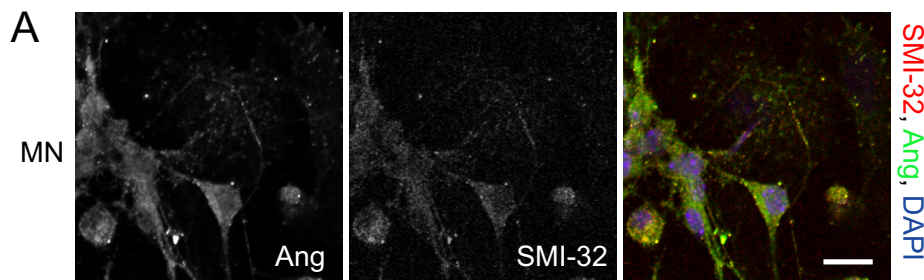

B
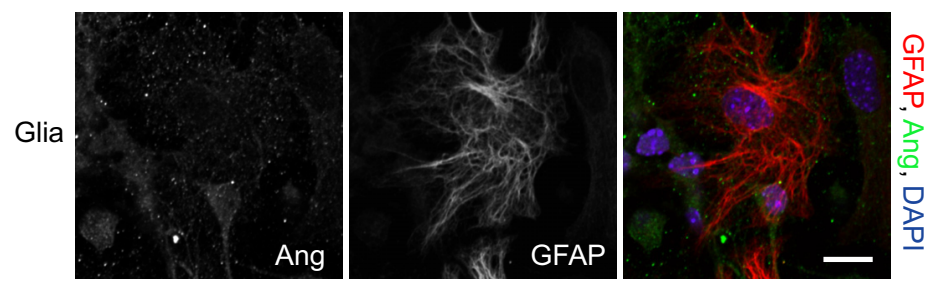

C
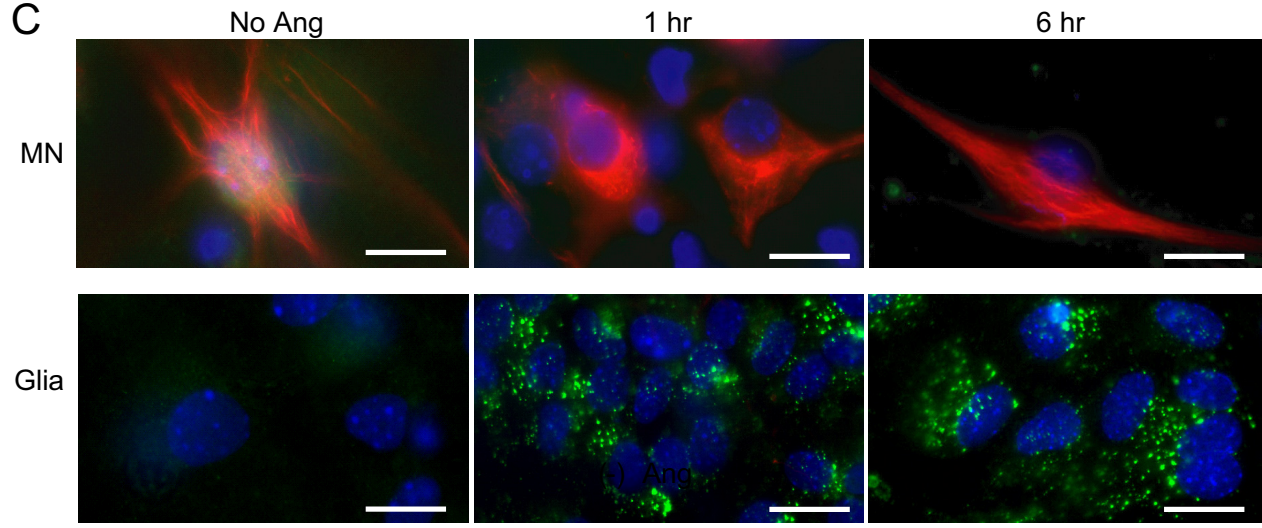

D
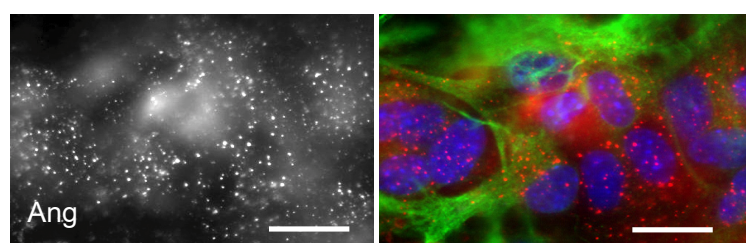

Ang, SMI-32, DAPI

fold expression

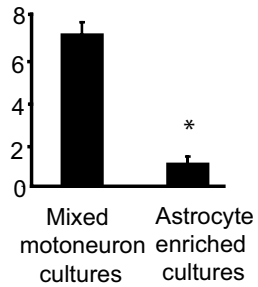

$\mathrm{E}$

Ang, GFAP, DAPI

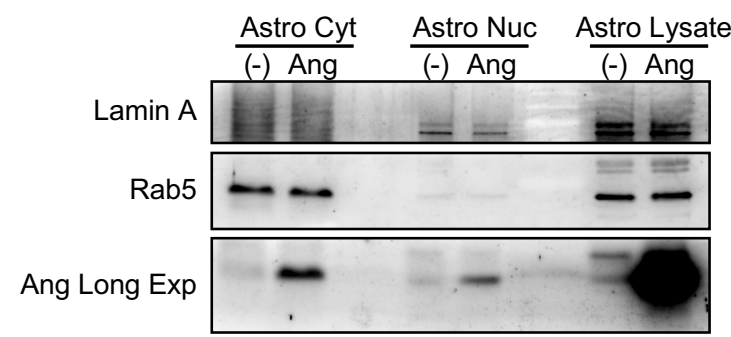

F

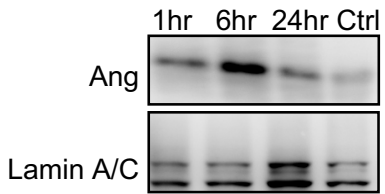

Figure 1. Uptake of recombinant angiogenin appears to be restricted to astroglia. $A$, Fluorescent images of DIV 7 primary mixed motoneuron cultures costained for SMI-32 or GFAP (red) and Ang (green) imaged from the same field at two different focal planes: neuronal (top) and glial (bottom). $B$, Quantitative real-time $P C$ R analysis showing murine ang 1 transcription levels in primary mixed motoneuron- and astrocyte-enriched cultures relative to $\beta$-actin mRNA ( ${ }^{*} p<0.05$; Student's $t$ test). Data are from $n=3$ cultures each. C, Immunocytochemistry of rhAng-treated (1 $\mu \mathrm{g} / \mathrm{ml}$ ) primary mixed motoneuron cultures costained for SMI-32 (red) and Ang (green). Images show staining in two different focal planes: neuronal (left) and glial (right). D, Representative image of rhAng-treated (1 $\mu \mathrm{g} / \mathrm{ml}$ ) primary astrocyte cultures costained for GFAP (green) and Ang (red). E, Western blot of rhAng-treated ( $1 \mu \mathrm{g} / \mathrm{ml}$ ) primary astrocyte lysate fractionated into cytosolic (Astro (yt) and nuclear (Astro Nuc) fractions probed for Lamin A (nuclear marker), Rab5 (cytosolic protein), and Ang [Long exposure blot shown for Ang (Ang Long Exp)]. F, Western blot showing the kinetics of nuclear translocation of rhAng over a $24 \mathrm{~h}$ time course uptake in primary astrocytes. Scale bars, $10 \mu \mathrm{m}$. All experiments were performed in duplicate with similar results.

robust and rapid vesicular uptake of angiogenin (Fig. 1C, bottom). We also examined rhAng uptake in primary motoneuron cultures treated with physiologically relevant stressors vulnerable to angiogenin-mediated neuroprotection. However, under AMPA-induced excitotoxic stress, we were again unable to detect any change to angiogenin immunoreactivity in neurons treated with rhAng (data not shown).
Using primary astroglial cultures, we found that angiogenin uptake occurred in cells costaining with the astrocyte marker GFAP (Fig. 1D). Angiogenin uptake in primary astroglial cultures was measured from $30 \mathrm{~min}$ and continued for the duration of the $24 \mathrm{~h}$ time course (Fig. 1C, compare glial planes at 1 and $6 \mathrm{~h}$ ). Using confocal laser microscopy we found that once internalized, angiogenin immunoreactivity appeared to remain initially se- 
questered within cytosolic vesicles and restricted from the nucleus and later entered the nucleus (data not shown). Subcellular fractionation experiments of samples obtained after $24 \mathrm{~h}$ of uptake confirmed these observations and demonstrated that rhANG was taken up into the cytosol, and that a fraction of rhAng was present in the nucleus (Fig. $1 E$ ). Nuclear uptake of rhAng in astrocytes was observed as early as $1 \mathrm{~h}$ after treatment, and peaked after $6 \mathrm{~h}$ of exposure to rhAng (Fig. $1 F$ ).

We also examined uptake using fluorescein-labeled rhAng (flrhAng; Kieran et al., 2008). However, again we were unable to detect uptake in motoneurons from $30 \mathrm{~min}$ through $24 \mathrm{~h}$ (Fig. $2 \mathrm{~A}$, left, shown at $1 \mathrm{~h}$ ). Instead, we observed robust fl-rhAng uptake in non-neuronal cells of the glial plane (Fig. $2 \mathrm{~A}$, middle), which could also be correlated with GFAP costaining (Fig. 2A, right). Figure $2 B$ provides a quantitative analysis of fl-rhAng uptake in GFAP-positive cells.

Endocytosis was dependent on an intact actin cytoskeleton and occurred in an energy-dependent manner, as treatment with the actin-destabilizing agent CytoD ( $1 \mu \mathrm{g} / \mathrm{ml}$; Fig. $2 C$, middle), or treatment with the mitochondrial toxin sodium azide $(10 \mathrm{~mm}$; Fig. $2 C$, right) inhibited fl-rhAng uptake compared with control cultures (Fig. $2 C$, left). Figure $2 D$ provides a quantitative analysis of fl-rhAng uptake (after $1 \mathrm{~h}$ ) in GFAP-positive cells in the presence or absence of CytoD. Treatment with azide induced a complete inhibition of fl-rhAng uptake. As a negative control, excess fluorescein used at the same concentration required for rhAng labeling was applied to primary motoneuron cultures, but was not taken up by neurons or astroglia (data not shown). Collectively, these data show that exogenous angiogenin is poorly internalized by primary motoneurons over $24 \mathrm{~h}$; in contrast astrocytes are primed to efficiently endocytose angiogenin and may be pivotal in mediating the neuroprotective output of angiogenin.

\section{Motoneurons secrete angiogenin under stress, which is taken up by glia}

Angiogenin is a secreted protein originally purified and sequenced from the conditioned medium of an adenocarcinoma cell line (Fett et al., 1985). The fact that neurons are naturally rich in angiogenin, but do not efficiently endocytose the protein, whereas as astroglia are deficient in angiogenin and appear primed to take up the protein, provoked our hypothesis that neurons release angiogenin as a signal to astroglia. We therefore investigated the trafficking of angiogenin between neurons and astroglia to define a presumed endogenous signaling route.

We first investigated endogenous angiogenin signaling in primary motoneuron cultures and used serum withdrawal as a stress stimulus to identify whether astrocytes in close proximity to motoneurons showed upregulated angiogenin endocytosis. Under control conditions, SMI-32-positive motoneurons (Fig. 2 E, top left) were enriched for angiogenin compared with neighboring astroglia (Fig. 2E, top right) (Greenway et al., 2006) shown in different focal planes of the same field. Under serum withdrawal (Fig. 2E, bottom left), we observed that motoneurons became slightly shrunken in appearance but did not show condensed or fragmented nuclei or signs of cell death; however, neighboring astroglia showed an obvious increase in the size and abundance of angiogenin-positive vesicles (Fig. $2 \mathrm{E}$, bottom right) from 17 puncta per cell $( \pm 9)$ in full medium to 58 puncta per cell $( \pm 23)$ under serum withdrawal (data from $n=20$ and 40 cells in two separate experiments). To quantify angiogenin secretion from motoneurons, we conditioned medium from primary motoneuron cultures for analysis by Western blot, but could not obtain sufficient quantities for biochemical analyses (data not shown). Therefore we transitioned to motoneuronal NSC34 cells, a primary motoneuron and neuroblastoma fusion cell line (Cashman et al., 1992), to further study angiogenin secretion.

NSC34 cells have been widely used as a model to study biochemical properties of motoneurons (Turner et al., 2005). By Western blotting, we observed that NSC34 cells express angiogenin under normal conditions and induce angiogenin protein under serum withdrawal stress (Fig. 2G, left), similar to primary motoneuron cultures (Fig. 2 F). Moreover, medium conditioned by NSC34 cells cultured under serum withdrawal contained detectable levels of angiogenin protein, measured by Western blotting (Fig. 2G, right). It was not possible to directly measure angiogenin secretion in the presence and absence of serum due to the disruption caused by serum proteins during electrophoresis. Thus, since angiogenin contains a signal peptide for secretion, we used BFA to disrupt endoplasmic reticulum (ER) to Golgi protein transport and confirm angiogenin secretion as an active cellular process (Fig. 2G, far right). We found that BFA used at $0.3 \mu \mathrm{M}$ was sufficient to inhibit angiogenin secretion, without causing cell permeabilization over $22 \mathrm{~h}$, indicated by the lack of $\alpha$-tubulin protein in conditioned medium. Consistent with previous reports, we found that NSC34 cells secreted actin, which was not affected by BFA treatment (Lafon-Cazal et al., 2003); hence it served as a second negative control. Collectively, these findings show that endogenous angiogenin is upregulated by serum withdrawal in NSC34 cells and secreted by a mechanism relying on ER and Golgi function.

We next determined whether angiogenin derived from NSC34 cultures could be taken up by astrocytes. Under serum withdrawal, purified astroglia showed very little endogenous angiogenin staining by immunocytochemistry (Fig. 2G, left). However, when astroglia were treated with medium conditioned by NSC34 cells cultured under serum withdrawal, they showed robust vesicular uptake of the protein, similar to that observed within astroglia in close proximity to primary motoneurons in serum-deprived cultures (Fig. $2 G$, right).

To confirm the secretion of angiogenin from NSC34 cells and establish a model to test the paracrine functions of WT and ALSassociated angiogenin mutants, we characterized the expression and secretion of overexpressed human angiogenin (ANG). ANG WT and K40I RNase inactive constructs were transfected into NSC34 cells and analyzed for intracellular and extracellular protein by Western blotting (Greenway et al., 2006; Sebastià et al., 2009). We found that, under serum withdrawal, both WT and mutant angiogenin were expressed and secreted to the same extent intracellularly and accumulated to the same extent extracellularly (Fig. 3A). By immunocytochemistry, we observed that overexpressed angiogenin localized to two distinct subcellular regions: a perinuclear reticulate structure and puncta in the putative growth cone of NSC34 cells resembling secretory granules (Fig. 3B, left) (Burgoyne and Morgan, 2003; Ohsawa et al., 2003). Treatment with BFA $(3 \mathrm{~h}, 0.3 \mu \mathrm{M})$ disrupted the formation of angiogenin granules in the peripheral regions of the cell from 100 to $18.5 \%$ (Fig. $3 B$, right; Fig. $3 C$ ). As a negative control, overexpressed GFP did not localize to the ER or Golgi, but distributed diffusely throughout the cytosol and nucleus (data not shown). By loading the same proportion of protein from intracellular and extracellular lysates, we quantified that angiogenin was secreted at greater than twofold than the amount which was retained intracellularly (Fig. 3D). Finally, we found that astrocytes treated with conditioned medium from NSC34 cultures overexpressing 
A
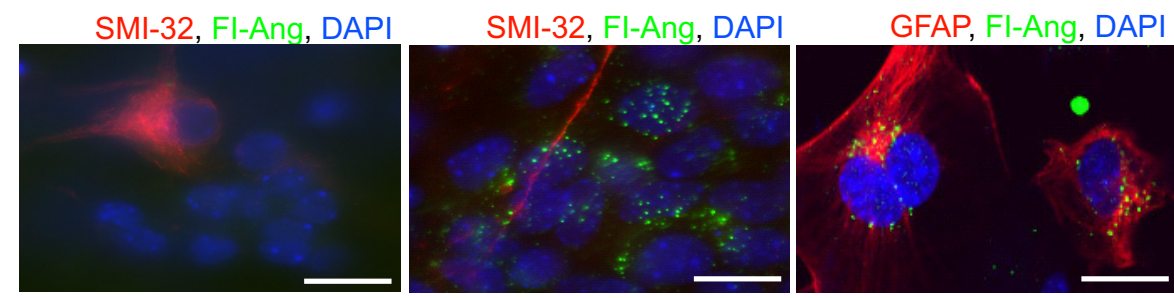

B

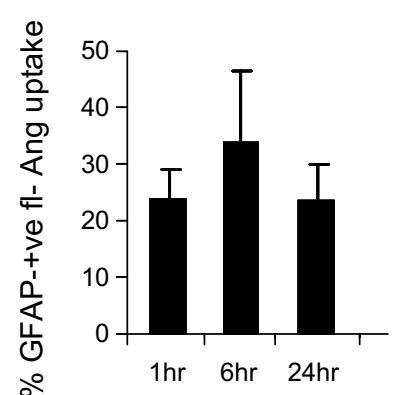

C

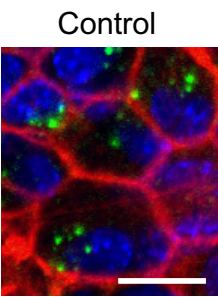

CytoD

NaN3
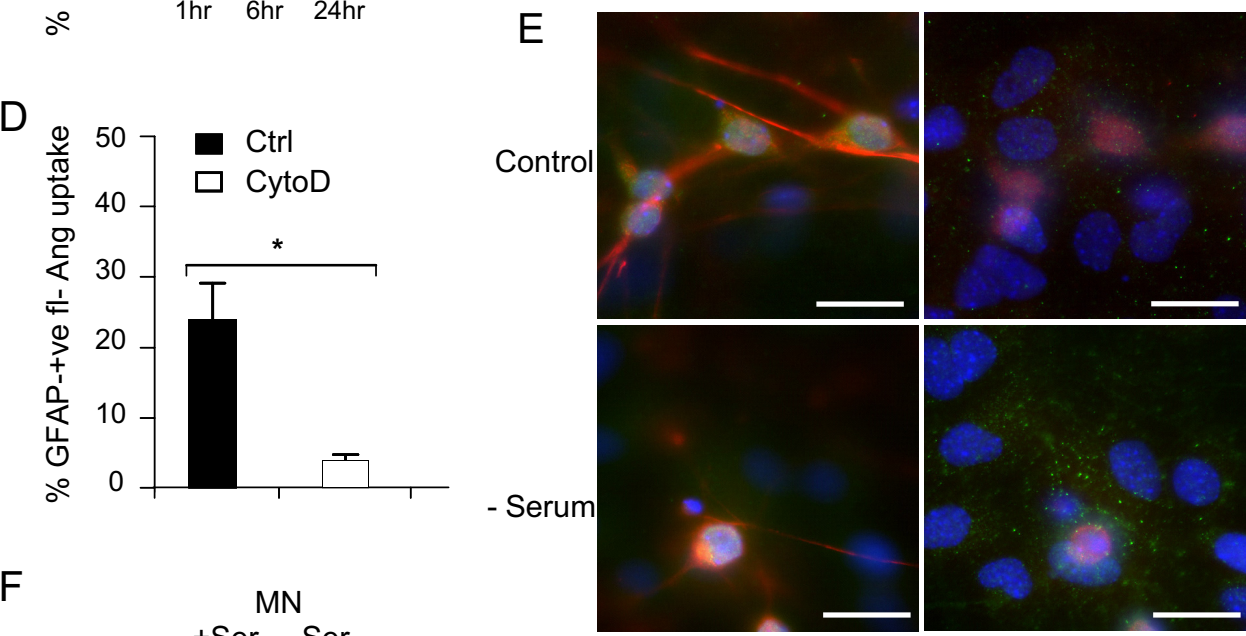

F
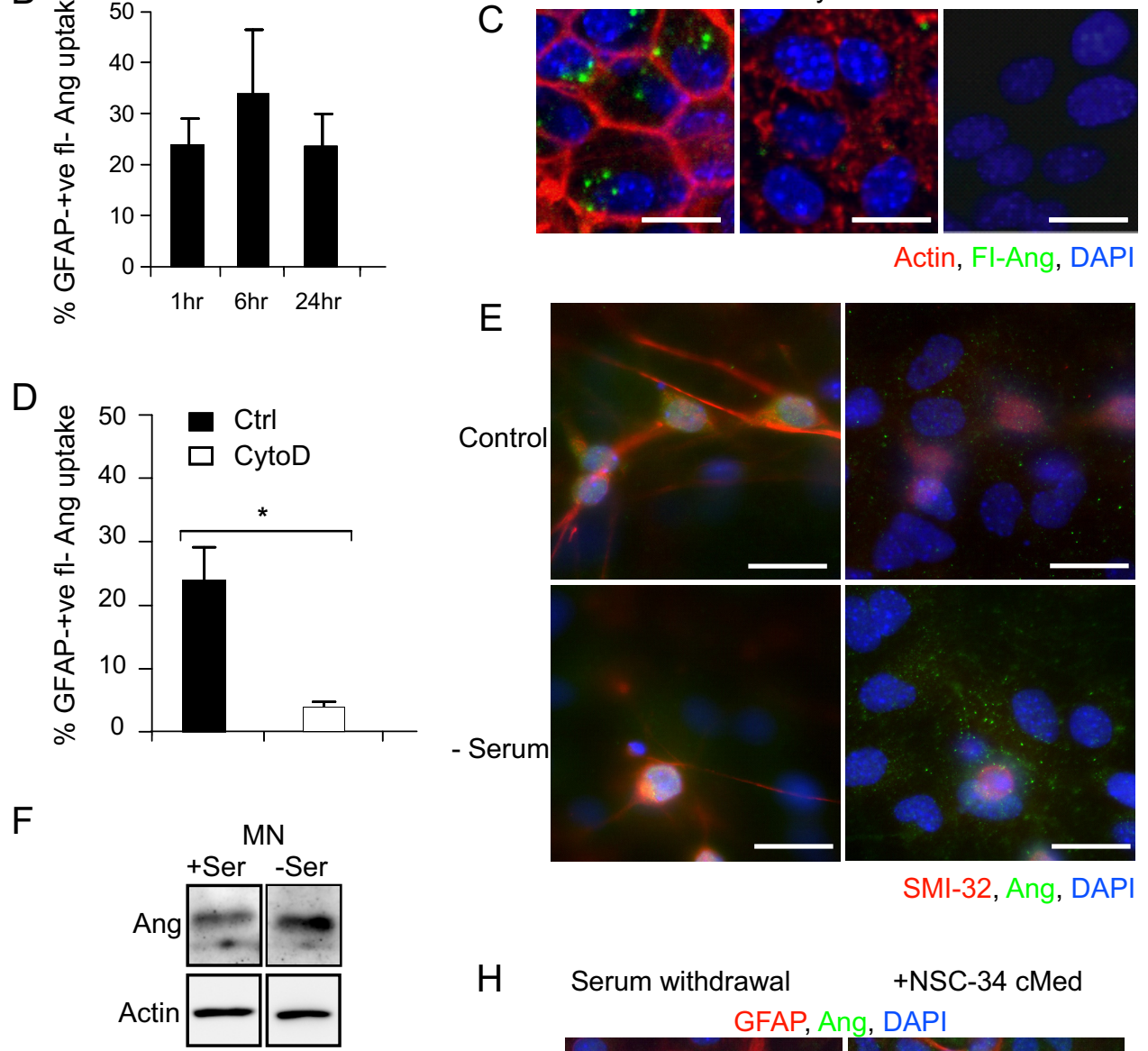

Actin, FI-Ang, DAPI

SMI-32, Ang, DAPI

$\mathrm{H}$

Serum withdrawal

+NSC-34 cMed

G
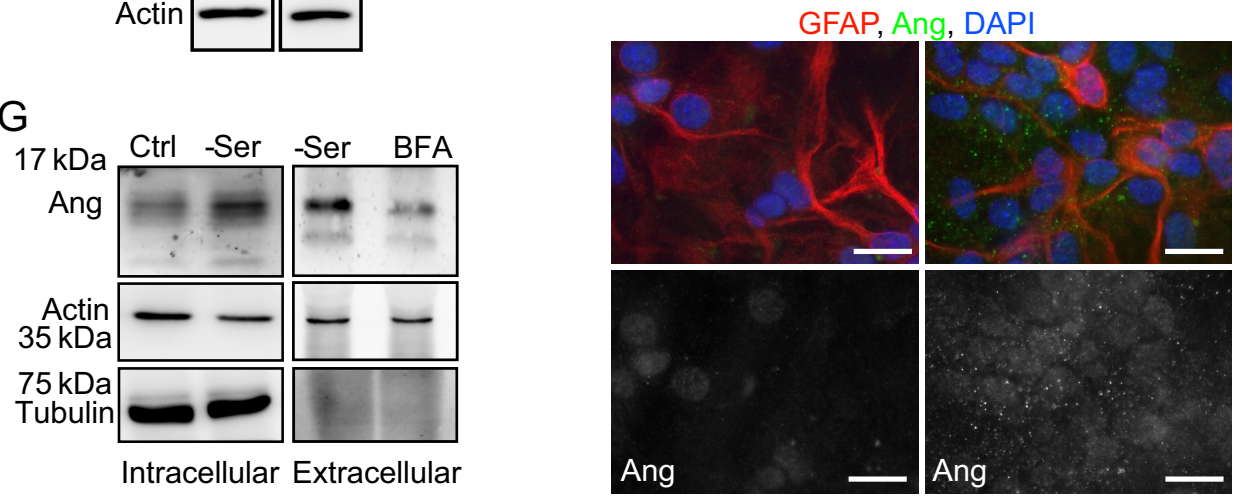

Figure 2. Uptake of rhAng by primary mixed motoneuron cultures is an actin- and energy-dependent process. $\boldsymbol{A}$, Representative images of neuronal plane of fluorescein-conjugated rhAng (fl-Ang)-treated primary motoneuron cultures stained for SMI-32 (red), compared with glial plane. B, Quantification of fl-Ang uptake by GFAP-positive astroglia in primary mixed motoneuron cultures over a $24 \mathrm{~h}$ time course. C, Uptake of fl-Ang in primary mixed motoneuron cultures with or without CytoD pretreatment $(1 \mu \mathrm{g} / \mathrm{ml} ; 1 \mathrm{~h} \mathrm{preincubation;} \mathrm{stained} \mathrm{red}$ for actin) or pretreated with $\mathrm{NaN}_{3}(10 \mathrm{~mm})$. D, Quantification of fl-Ang uptake by GFAP-positive astroglia in primary mixed motoneuron cultures with or without CytoD pretreatment (1 $\mu \mathrm{g} / \mathrm{ml} ;{ }^{*} p \leq 0.05$; mean $\pm S D$; data from $10-20$ cells in two independent experiments). $\boldsymbol{E}$, Representative images of primary mixed motoneuron cultures in full medium or under serum withdrawal (SMI-32, red; Ang, green). $\boldsymbol{F}$, Western blot detecting Ang in lysates of mixed motoneuron cultures in full medium (Ctrl) or under serum withdrawal (-Ser; left). $\boldsymbol{G}$, Western blot detecting Ang in lysates of NSC34 cells cultured in full medium (Ctrl) or under serum withdrawal ( - Ser; left) and supernatant with or without BFA cotreatment (0.3 $\boldsymbol{\mu M}$, right). $\boldsymbol{H}$, Representative images of primary astrocyte cultures under serum withdrawal or treated with NSC34-conditioned medium (cMed, GFAP red; Ang green). All experiments were performed in duplicate with similar results. Scale bars, $10 \mu \mathrm{m}$. 
A

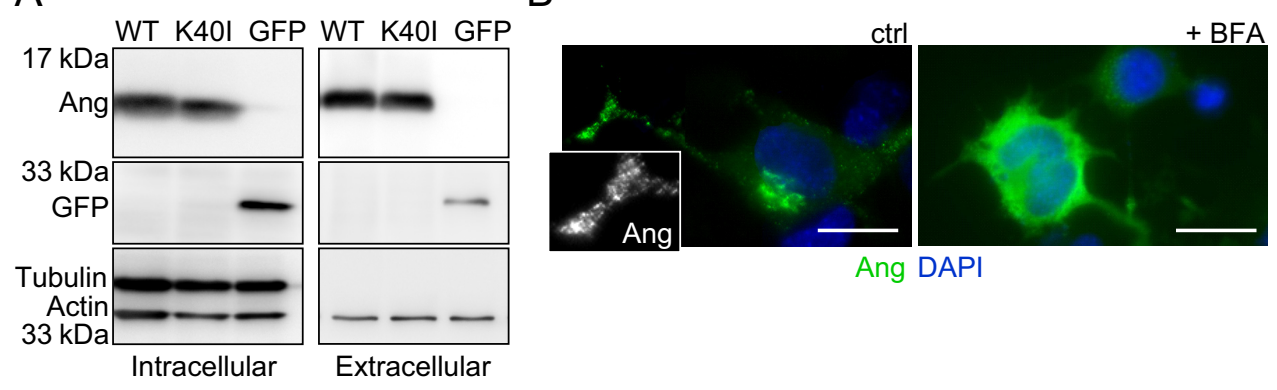

C

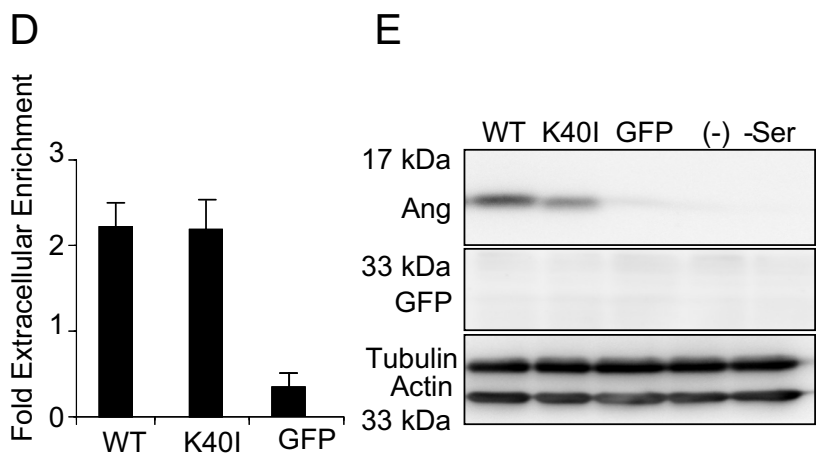

Figure 3. Motoneuron-like NSC34 cells express and secrete angiogenin. $\boldsymbol{A}$, Western blot detecting Ang and GFP in lysate (left) and supernatant (right) collected from NSC34 cells overexpressing wt Ang (WT), Ang K40I, or GFP during serum withdrawal. B, Representative images of NSC34 cells overexpressing hAng (green), cotreated with BFA (0.3 $\mu \mathrm{M})$. C, Quantification of hAng in transfected NSC34 cells treated with BFA $\left(0.3 \mu \mathrm{m} ;{ }^{*} p \leq 0.05\right)$. Data are from $10-15$ cells in two independent experiments. $\boldsymbol{D}$, Quantification of angiogenin secretion by NSC 34 cells overexpressing both WT and K40I mutant in comparison with GFP. Experiment was performed in triplicate. E, Western blot detecting Ang and GFP in lysate of primary astrocytes treated with supernatant from NSC34 cells overexpressing hAng. Experiment was performed in duplicate with similar results. Scale bars, $10 \mu \mathrm{m}$.

WT and K40I ANG showed angiogenin uptake by Western blotting; however, GFP uptake was not detected (Fig. 3E). Densitometrical analysis of WT and K40I angiogenin protein accumulation in astrocytes relative to WT and K40I angiogenin levels within the respective conditioned medium revealed, in two separate experiments, a 45 and $48 \%$ reduction in K40I angiogenin accumulation in astroglia compared with WT angiogenin.

Collectively, these data prove that NSC34 cells express and secrete endogenous and overexpressed angiogenin by a classical secretory pathway, and that secreted WT, and to a lesser extent K40I angiogenin, are efficiently endocytosed by astroglia.

\section{Angiogenin confers neuroprotection in paracrine}

Our group has previously demonstrated that the exogenous addition of angiogenin protects primary motoneuron excitotoxic effects of AMPA (Kieran et al., 2008). Since angiogenin was preferentially endocytosed by astroglia, we next tested whether the neuroprotection afforded by angiogenin was mediated in a paracrine way.

To this end, we generated conditioned medium from primary mixed motoneuron cultures treated with rhAng according to the scheme outlined in Figure $4 A$. In brief, primary mixed cultures were incubated with $100 \mathrm{ng} / \mathrm{ml} \mathrm{rhAng}$ or heat-denatured rhAng for $6 \mathrm{~h}$, washed four times, and incubated for a further $18 \mathrm{~h}$ in

A
B

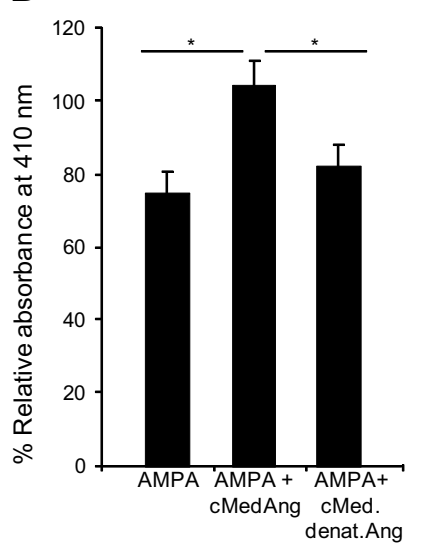

C

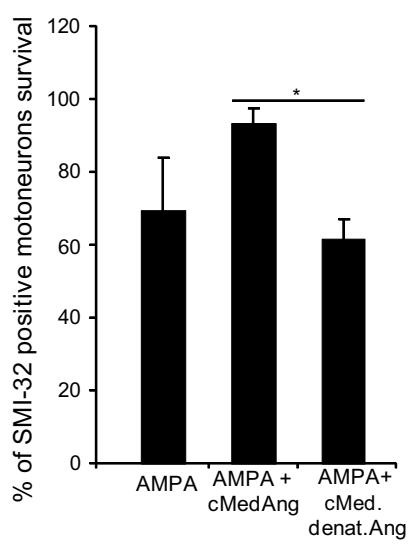

Figure 4. Angiogenin mediates neuroprotection through a paracrine pathway in primary mixed motoneuron cultures. $\boldsymbol{A}$, Scheme depicting generation of rhAng-conditioned medium (cMed, $100 \mathrm{ng} / \mathrm{ml}$ ) to test paracrine protection. MTT assay $(\boldsymbol{B})$ and direct counts $(C)$ of motoneuron survival in primary mixed motoneuron cultures treated with AMPA $(50 \mu \mathrm{M})$, AMPA and cMedAng, or AMPA $(50 \mu \mathrm{M})$ and $\mathrm{cMed}$ from denatured rhAng-treated cultures (cMed denat. Ang; ${ }^{*} p \leq 0.05$; mean $\pm \mathrm{SD}$; data from $n=$ 4-6 cultures in 3 independent experiments).

complete Neurobasal medium. The neuroprotective activity of conditioned medium (cMed Ang or cMed denat Ang) was tested against AMPA-induced excitotoxicity by applying it to sister mixed motoneuron cultures for 30 min before AMPA (50 $\mu \mathrm{M})$ treatment for $24 \mathrm{~h}$. By MTT assay, we first observed that cMed Ang significantly protected the viability of mixed motoneuron cultures compared with AMPA and cMed denat Ang (Fig. 4B). By SMI-32 immunocytochemistry we also observed that cMed Ang increased the number of surviving motoneurons treated with AMPA, statistically significant compared with cMed denat 

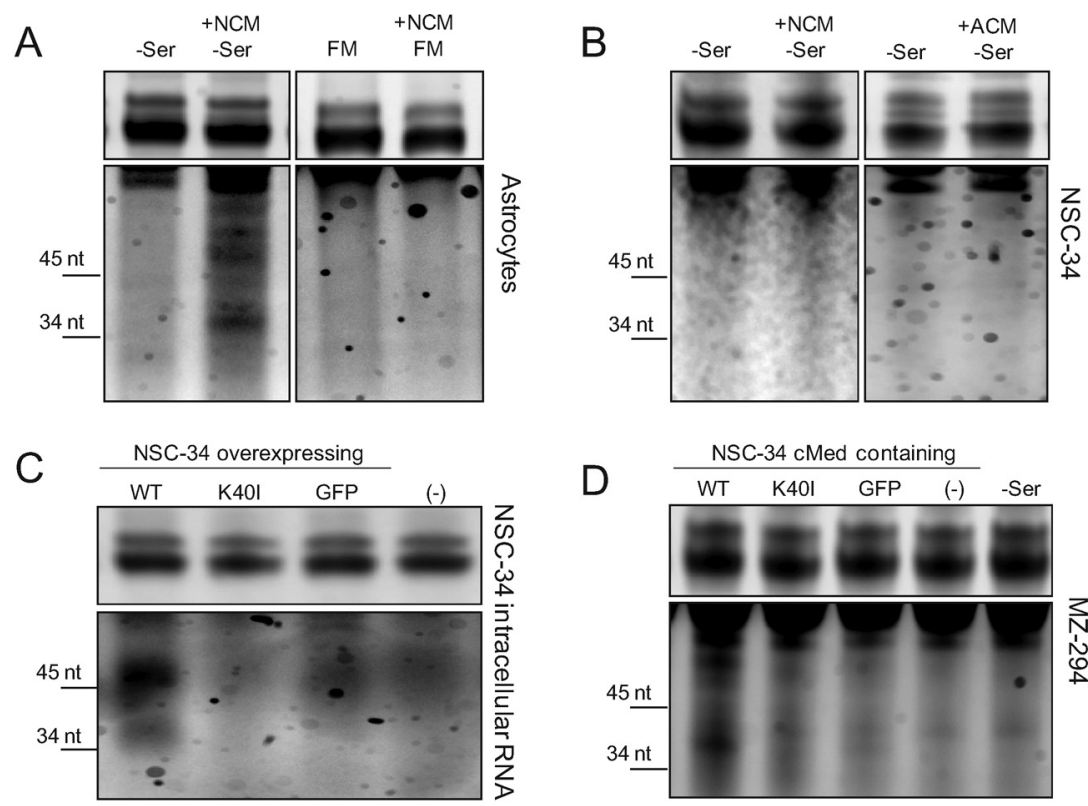

E
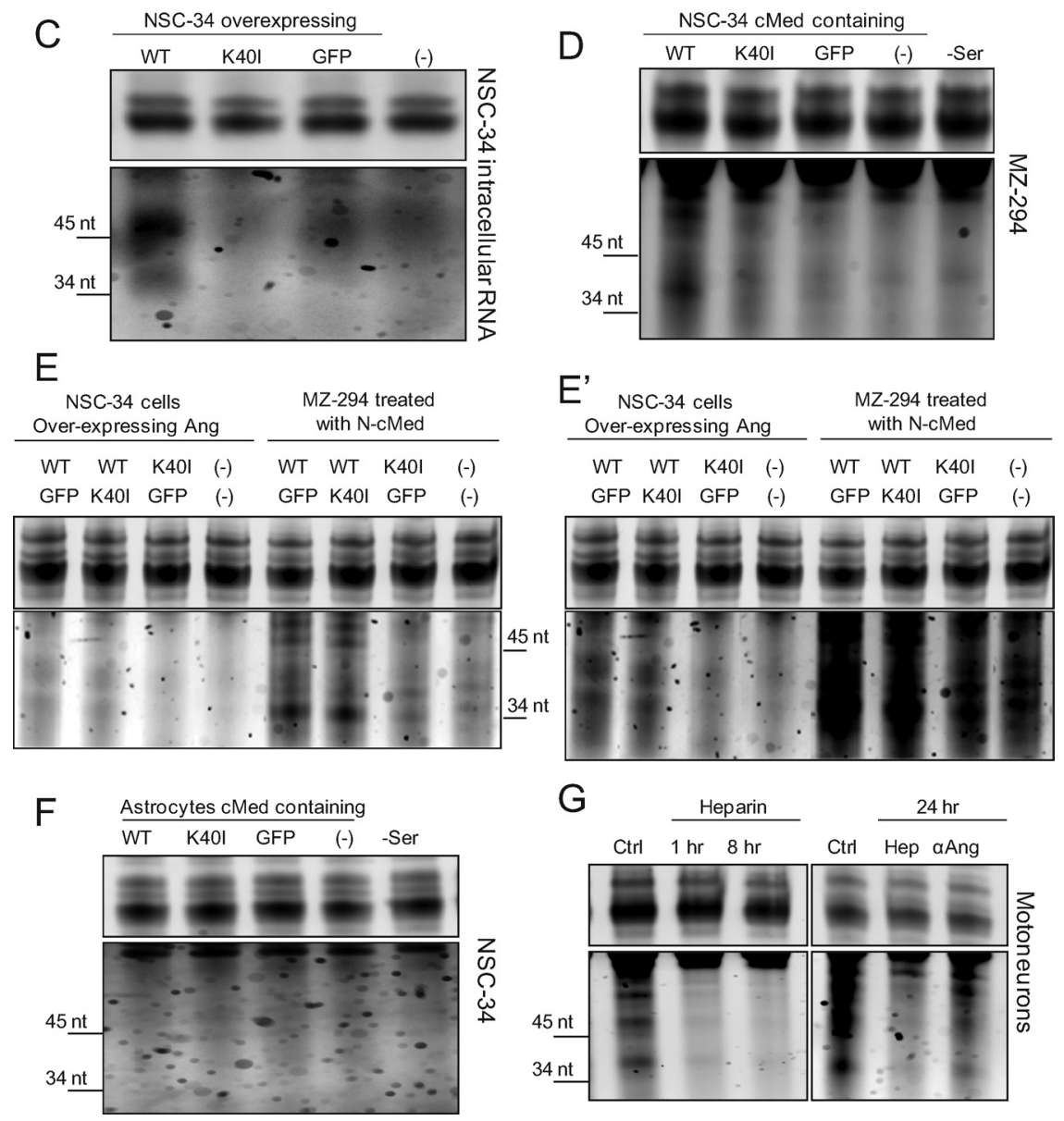

Figure 5. RNA processing in paracrine is stress inducible and restricted to a protein secreted by neurons acting specifically on astroglia. $\boldsymbol{A}$, RNA gels showing cleavage of astrocyte RNA collected under serum withdrawal ( - Ser, left) or in full medium (FM; right) after treatment with NSC34-conditioned medium (NCM; for 3 h). B, NSC34 RNA collected under serum withdrawal treated (3 h) with NSC34 (left)- or astrocyte (right)-conditioned medium (NCM/ACM; 24 h). C, Intracellular RNA cleavage in NSC34 cells overexpressing wt hAng, Ang K40I, or GFP. D. Human MZ-294 astrocytoma RNA collected under serum withdrawal treated ( $3 \mathrm{~h}$ ) with conditioned medium (cMed) collected from NSC-34 cells overexpressing wt hAng, Ang K40l, or GFP (24 h). E, Comparison of endogenous (NSC-34) and paracrine (MZ-294) RNA cleavage fragments and demonstration of lack of dominant-negative effect of Ang K40I on Ang-induced RNA cleavage. NSC-34 cells were expressed with equal amounts of wt hAng, Ang K40l, or GFP as indicated. Experiments were performed as described in $\boldsymbol{C}$ and $\boldsymbol{D}$. $\boldsymbol{E}^{\prime}$, Represents the same gel overexposed to highlight the endogenous cleavage products in NSC34 cells. $F$, NSC34 RNA collected under serum withdrawal treated ( $3 \mathrm{~h}$ ) with conditioned medium collected from primary astrocytes overexpressing wt hAng, Ang K40l, or GFP (24 h). All experiments were performed in duplicate with similar results. G, RNA cleavage in primary mixed motoneuron cultures under normal culture conditions (Ctrl) or treated with heparin ( $1 \mu \mathrm{g} / \mathrm{ml} ; 1$ or $8 \mathrm{~h}$; left; performed in triplicate with similar results) and treated with heparin (Hep) or an Ang-inactivating antibody ( $\alpha \mathrm{Ang} ; 2 \mu \mathrm{g} / \mathrm{ml} ; 24 \mathrm{~h}$; right).

Ang (Fig. 4C). These results confirm our previous observation that angiogenin is a neuroprotective factor for motoneurons, but demonstrate that the neuroprotective activity of angiogenin in primary motoneuron cultures is mediated in paracrine.

\section{Angiogenin mediates stress-induced RNA cleavage in astrocytes}

Previous work demonstrated that the neuroprotective activity of angiogenin is lost in mutants that are deficient in its RNase activity, suggesting that neuroprotection requires RNA cleavage by angiogenin (Wu et al., 2007; Kieran et al., 2008; Sebastià et al., 2009). Angiogenin is known to cleave tRNA in a variety of mammalian cell lines (Fu et al., 2009; Yamasaki et al., 2009). We were therefore interested in exploring the effect of paracrine angiogenin signaling on RNA cleavage in neurons and astrocytes.

We first assayed the RNase activity of NSC34-conditioned medium using astroglial cultures as a substrate. NSC34 cells were cultured in full medium or under serum withdrawal for $24 \mathrm{~h}$, the conditioned medium (NCM) was collected and applied to astroglia for $3 \mathrm{~h}$, and RNA cleavage was assessed by electrophoresis (Fig. 5A) (Yamasaki et al., 2009). We found that serum withdrawal NCM, but not full medium NCM, induced intracellular RNA fragmentation (Fig. 5A), indicating that NSC34 cells upregulate and secrete a factor which modifies the RNA profile of astrocytes in paracrine under stress. Intriguingly, the resulting RNA cleavage products $(\sim 40, \sim 50$, and $\sim 60 \mathrm{nt})$ were not of a size consistent with that previously reported for tRNA cleavage ( $~ 35$ and $\sim 45 \mathrm{nt}$; Yamasaki et al., 2009). These data suggest that neural cells secrete factors under stress conditions that induce RNA cleavage in astrocytes.

To determine whether NSC34-mediated paracrine RNA cleavage could operate in an autocrine manner, we tested the activity of serum withdrawal NCM on sister NSC34 cultures (Fig. 5B, left). Under these conditions, we could not detect any RNA cleavage, indicating that astrocytes are uniquely sensitive to the NSC34-derived RNase in this assay. We also conducted the experiment in reverse to test whether astrocytesecreted factors could induce RNA cleavage in NSC34 cells (Fig. 5B, right). Primary mouse astrocyte cultures were incubated for $24 \mathrm{~h}$ in either full medium or under serum withdrawal after which the conditioned medium (ACM) was applied to NSC34 cells. Again, however, we could not observe RNA cleavage in NSC34 cultures. These results suggested that RNA processing under stress does not operate from neuron to neuron or from astrocyte to neuron, but in a unidirectional manner from neurons to astrocytes.

We next tested the ability of overexpressed human ANG to induce RNA cleavage in astroglial cultures in paracrine. We first characterized the RNase activity of overexpressed ANG on intracellular RNA and found that WT ANG, but not K40I RNase in- 
A

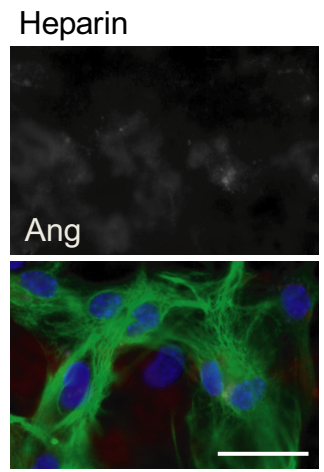

C

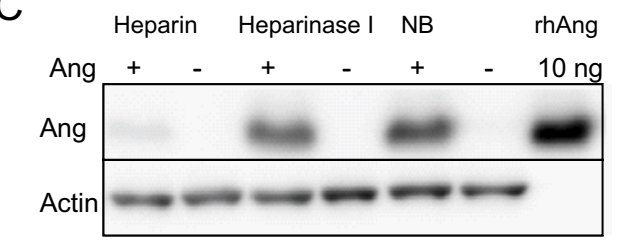

$\mathrm{E}$

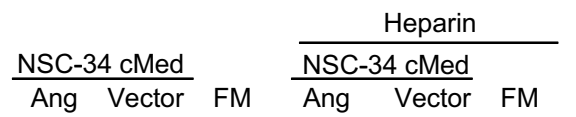

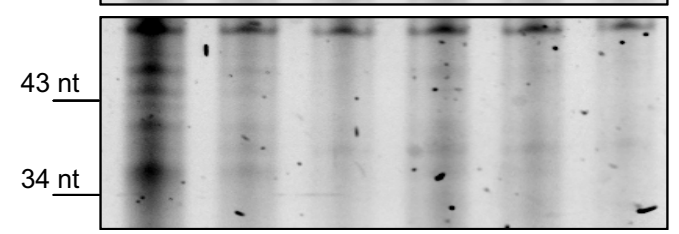

G

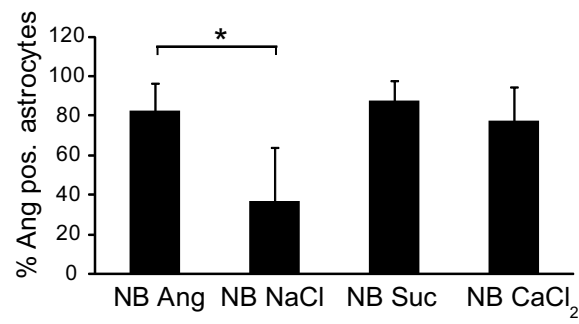

B

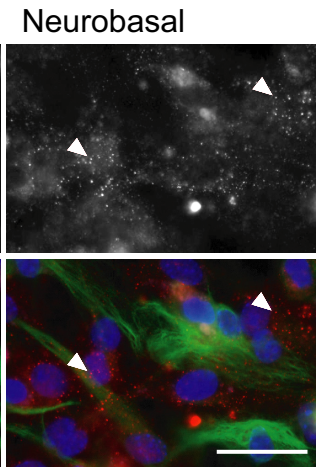

Ang GFAP DAPI
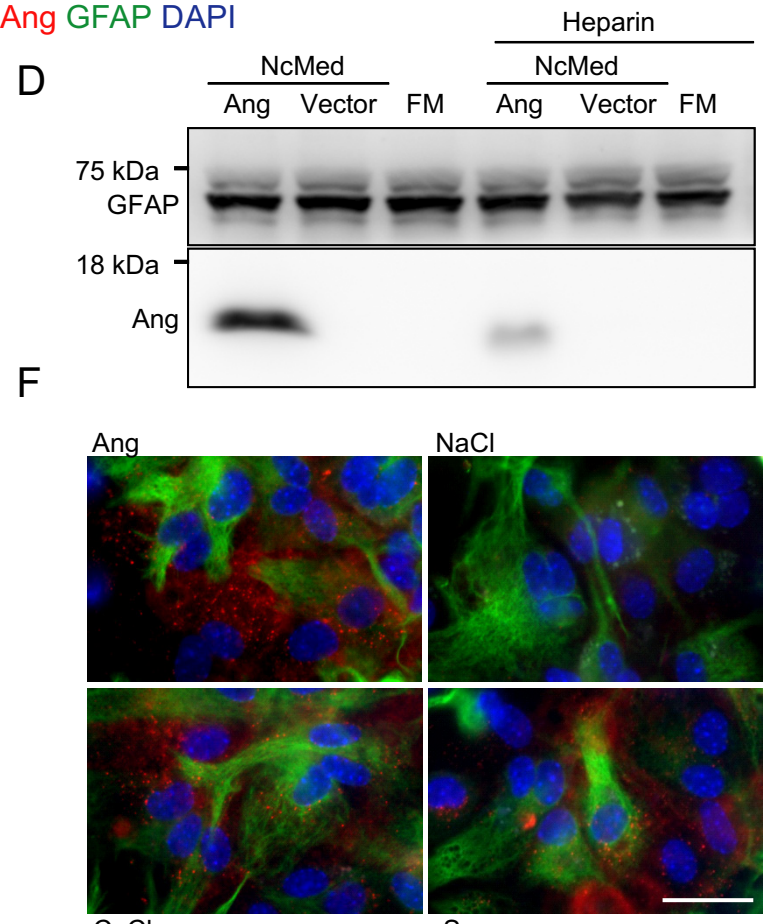

$\mathrm{NaCl}$

$\mathrm{CaCl}_{2}$

$\mathrm{H}$
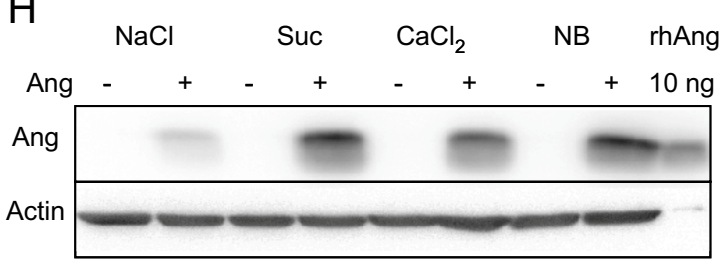

Figure 6. Angiogenin is internalized by astrocyte cultures in a heparin- and NaCl-dependent manner. $A$, Immunocytochemistry of rhAng-treated ( $1 \mu \mathrm{g} / \mathrm{ml} ; 1 \mathrm{~h}$; red) primary astrocytes with or without pretreatment with heparin $\left(10 \mu \mathrm{g} / \mathrm{ml} ; 2 \mathrm{~h}\right.$ preincubation) or heparinase I $\left(2.5 \mathrm{U} / \mathrm{ml} ; 2 \mathrm{~h}\right.$ preincubation, arrowheads indicate angiogenin-containing vesicles), quantification $\left(\boldsymbol{B},{ }^{*} p \leq 0.05 ;\right.$ mean $\pm S D ; n=3$ separate experiments) and Western blot (C, performed in duplicate with similar results). $\boldsymbol{D}$, Uptake of hAng derived from NSC34 cells overexpressing wt hAng or control vector transfected by human astrocytoma with or without heparin $(10 \mu \mathrm{g} / \mathrm{ml})$ treatment by Western blotting [full medium control (FM), $3 \mathrm{~h}$; performed in duplicate with similar results]. E, RNA gel of same conditions (performed in duplicate with similar results). F, Immunocytochemistry of rhAng-treated $(1 \mu \mathrm{g} / \mathrm{ml} ; 1 \mathrm{~h} ;$ red) primary astrocytes in Neurobasal adjusted to DMEM values for NaCl, osmolarity (Suc), and CaCl 2 ( 3000 - 6400 mg/L NaCl, 235 - 335 mosm, $200-264 \mathrm{mg} / \mathrm{L} \mathrm{CaCl} ; 1 \mathrm{~h})$, quantification ( $\boldsymbol{G},{ }^{*} p \leq 0.05 ;$ mean $\pm \mathrm{SD} ; n=3$ separate experiments) and Western blot (H, performed in duplicate with similar results). Scale bars, $25 \mu \mathrm{m}$.

active $A N G$, induced RNA cleavage-consistent in size with previously reported tRNA halves (Yamasaki et al., 2009)—when overexpressed in NSC34 cells (Fig. 5C). We next tested the potency of secreted overexpressed human angiogenin to induce RNA cleavage in astroglia in paracrine (Fig. 5D). To avoid any potential species barriers, we applied NCM from human WT and K40I ANG overexpressing NSC34 cells to MZ-294 cells, a GFAPpositive human astrocytoma culture (Hetschko et al., 2008). We observed that WT, but not K40I ANG NCM, induced RNA cleavage in human astrocytes. Again, however, the cleavage fragments in human astrocytoma cells were not of a size consistent with tRNA cleavage, but consistent with size of fragments observed in serum withdrawal NCM-treated mouse astroglia (Fig. 5A).

To study the potential dominant-negative effect of ALSassociate angiogenin mutant K40I, we cotransfected NSC34 cells with both WT and K40I ANG (Fig. 5E). Cotransfection with GFP 

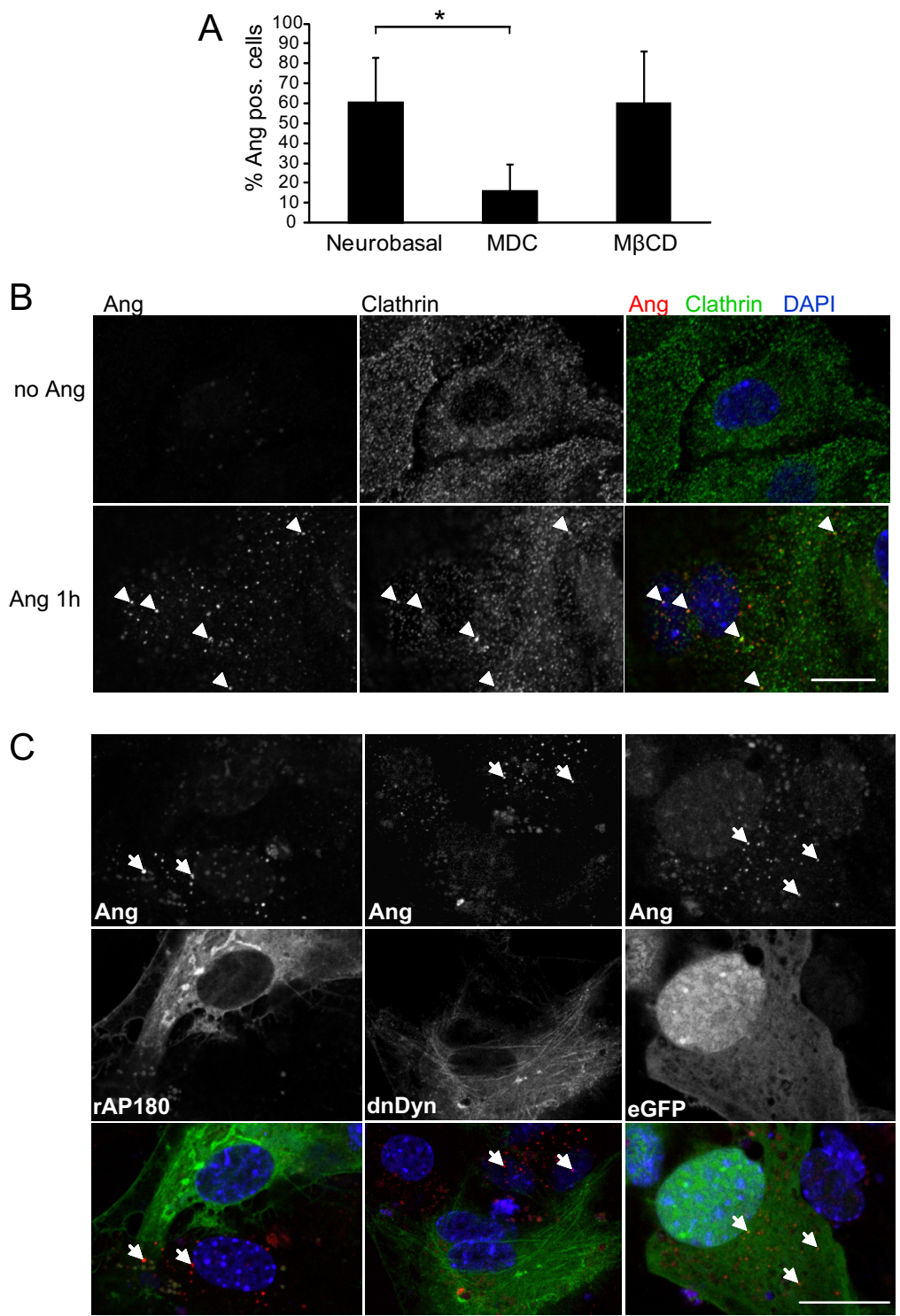

Ang rAP180 DAPI

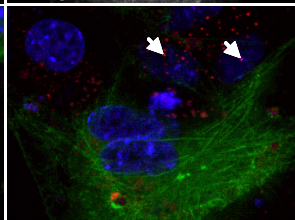

Ang dnDyn DAPI

Ang eGFP DAPI

Figure 7. rhAng internalization occurs via CME requiring dynamin for vesicle budding. $A$, Quantification of rhAng $(1 \mu \mathrm{g} / \mathrm{ml} ; 1 \mathrm{~h}$; red) uptake by primary astrocytes with or without pretreatment with $\operatorname{MDC}(0.2 \mathrm{mM})$ or $\mathrm{M} \beta \mathrm{CD}(0.24 \%$; both $1 \mathrm{~h}$ preincubation) in immunocytochemistry $\left({ }^{*} p \leq 0.05\right.$; mean $\pm S D ; n=3$ separate experiments, arrowheads indicate angiogenin-containing vesicles). $\boldsymbol{B}$, Confocal images showing angiogenin $(1 \mu \mathrm{g} / \mathrm{ml} ; 1 \mathrm{~h}$; red) colocalization with clathrin HC (green) staining in primary astrocyte cultures $(n=3)$. C, Confocal images of primary astrocytes transfected with rAP180 ( $24 \mathrm{~h}$; left; green) or dnDyn ( $24 \mathrm{~h}$; middle; green) compared with eGFP transfection treated with rhAng ( $1 \mu \mathrm{g} / \mathrm{ml} ; 1 \mathrm{~h} ;$ red; $n=3$; right, arrows indicate angiogenincontaining vesicles). Experiments were performed in duplicate with similar results. Scale bars, $25 \mu \mathrm{m}$.

was used as control. No inhibitory effect of K40I ANG over WT was observed both in the endogenous and the paracrine RNA cleavage. Figure $5 E^{\prime}$ shows a longer exposure of the same gel shown in Figure $5 E$ to highlight the difference in endogenous versus paracrine RNA cleavage.

We further investigated the directionality of angiogenin signaling between neurons and astroglia by conducting the experiment in reverse. Conditioned medium from astroglia overexpressing human WT and K40I ANG was applied to NSC34 cells. We could not detect any RNA cleavage in NSC34 cells induced by overexpressed human angiogenin in paracrine (Fig. $5 F$ ).

We next sought to determine whether intercellular motoneuron to astroglial angiogenin signaling was a natural feature of mixed primary motoneuron cultures, using RNA cleavage as a readout. We harvested total RNA from mixed cultures under control conditions and observed constitutive RNA fragmentation at $\sim 40, \sim 50$, and $\sim 60 \mathrm{nt}$, consistent with the paracrine RNA fragmentation pattern observed in mouse and human astrocytes (Fig. $5 A, D, G)$. We then tested whether this activity is mediated by secreted factors or by angiogenin in particular. Angiogenin has been characterized as a heparin-binding protein and is likely to require heparan sulfate proteoglycans to mediate uptake into astrocytes, a mechanism known to be involved in the uptake of other angiogenic molecules such as basic fibroblast growth factor/fibroblast growth factor-2 (bFGF/ FGF-2) and vascular endothelial growth factor (VEGF; Soncin et al., 1997; Kirkpatrick and Selleck, 2007). To determine whether constitutive RNA cleavage of mixed primary motoneuron cultures was caused by a paracrine factor consistent with this mechanism, we applied heparin ( $1 \mu \mathrm{g} /$ $\mathrm{ml}$ ) to the culture medium and observed a strong inhibition of RNA cleavage (Fig. 5G, left). This experiment proved that constitutive RNA cleavage occurred in paracrine, but also revealed the rapidity by which the RNA cleavage products are turned over (within $1 \mathrm{~h}$ of heparin treatment), and no RNA cleavage products were detectable. To prove that paracrine RNA cleavage in mixed motoneuron cultures was mediated by angiogenin, we used an angiogenininactivating antibody $(2 \mu \mathrm{g} / \mathrm{ml}$; see Materials and Methods), which we added to the culture medium. After a $24 \mathrm{~h}$ antibody treatment, the amount of RNA cleavage in primary motoneuron cultures was prominently reduced (Fig. 5G, right), demonstrating that motoneurons secrete angiogenin to induce RNA cleavage in astrocytes.

\section{Astroglia take up angiogenin via clathrin-mediated endocytosis}

To explain the astroglial-specific responses to secreted or exogenously applied angiogenin, we next decided to characterize the mechanism of angiogenin uptake into astroglia. We first confirmed that the addition of extracellular heparin to the cell culture medium or heparinase I preincubation inhibited the endocytosis of exogenously applied angiogenin in primary astroglial cultures. Heparinase I is a bacterial enzyme which removes heparan sulfates from the cell surface, thereby impeding heparan sulfate proteoglycan-aided endocytic events (Roghani and Moscatelli, 1992). By immunocytochemistry and Western blotting we observed that heparin $(1 \mu \mathrm{g} / \mathrm{ml})$ abolished the uptake of angiogenin, while the effect of heparinase I was less pronounced (Fig. 6A-C). We also confirmed this result in human astrocytoma cells using NCM from NSC34 cells expressing WT $A N G$, in which the addition of extracellular heparin potently inhibited the uptake of secreted angiogenin (Fig. 6D). Heparin inhibition of angiogenin uptake also correlated with a robust inhibition of paracrine RNA cleavage (Fig. $6 E$ ). 
The interaction of extracellular ligands with cell-surface heparan sulfate proteoglycans is disturbed under increasing concentrations of $\mathrm{NaCl}$ (Eckert and Ragg, 2003). Other reports suggested a strong dependence of endocytic events on both the osmolarity of the medium and both the sodium and calcium concentration (Daukas and Zigmond, 1985; Heuser and Anderson, 1989; Jiang and Chen, 2009). We used these features to further delineate the mechanism of angiogenin uptake in astrocyte cultures by increasing the sodium and calcium concentration and osmolarity of Neurobasal medium. Sodium and calcium concentrations and osmolarity were separately adjusted to those present in DMEM culture medium, a medium commonly used in tissue culture of neural and non-neural cells (3000-6400 mg/L $\mathrm{NaCl}, 200-264 \mathrm{mg} / \mathrm{L} \mathrm{CaCl}_{2}$, and 235-335 mosm) (Brewer et al., 1993). Interestingly, only increases in the concentration of $\mathrm{NaCl}$ resulted in the inhibition of angiogenin uptake, quantified by immunocytochemistry and Western blotting (Fig. $6 F-H)$.

From the punctate angiogenin staining pattern observed in our experiments, we set out to further investigate the mechanism of angiogenin uptake in astrocytes. To distinguish the two main endocytic routes, clathrin-mediated endocytosis (CME) or lipid raft-mediated endocytosis, we used MDC, a known inhibitor of CME (Gutiérrez-Ortega et al., 2008), or the cholesterol extraction agent $\mathrm{M} \beta \mathrm{CD}$, an inhibitor of lipid raft-mediated endocytosis (Vercauteren et al., 2010). MDC reduced the number of angiogenin vesicle-containing astroglia from 60 to $15 \%$ (Fig. $7 A$ ), whereas $\mathrm{M} \beta \mathrm{CD}$ showed no effect. Furthermore, we found that angiogenin-positive vesicles colocalized with clathrin as analyzed by confocal immunofluorescence microscopy (Fig. 7B, top; control experiments without angiogenin addition). Finally, expression of rAP180-GFP, a truncated and dominant-negative form of the AP180 clathrin adaptor (Doherty and McMahon, 2009), potently inhibited angiogenin uptake into astrocytes (Fig. 7C, left).

To confirm a general clathrin-dependent mechanism for angiogenin uptake we finally investigated the requirement for the small GTPase dynamin, which is essential for clathrin-dependent vesicle formation (Doherty and McMahon, 2009). We treated primary astrocyte cultures with dynasore, a small molecule inhibitor of dynamin which interferes with its GTPase activity (Macia et al., 2006; Tu et al., 2010), or transfected cells with a dominant-negative dynamin construct (Damke et al., 1994), before the addition of angiogenin. Both dominant-negative dynamin (Fig. $7 C$, middle) and dynasore (Fig. 8A,B) inhibited angiogenin uptake in mouse astroglia cultures, thereby showing a dependency on dynamin for the uptake mechanism.

Finally, we confirmed that this uptake mechanism is vital to angiogenin endocytosis and paracrine RNase cleavage and operated also in human cells. NCM from NSC34 cells expressing WT ANG was added in the absence or presence of elevated sodium chloride or dynasore. Both $\mathrm{NaCl}$ and dynasore robustly inhibited human angiogenin-mediated, paracrine RNA cleavage in human astro- cytoma cells (Fig. 8C). Collectively, these data show that angiogenin endocytosis is a clathrin-dependent, heparan sulfate proteoglycanassisted mechanism and that disruption to either of these components inhibits angiogenin endocytosis and concomitant paracrine RNA cleavage.

\section{The receptor for angiogenin uptake into astrocytes is} syndecan 4

To delineate the specificity of angiogenin uptake into astroglia, we decided to identify its receptor on astroglia. Cell surface heparan sulfate proteoglycans are contained within either the syndecans, which contain a single transmembrane domain, or the glypicans, which are tethered to the plasma membrane with a glycosylphosphatidylinositol anchor (Kirkpatrick and Selleck, 2007). Although these receptors lack catalytic activity, syndecan 4 is unique in being capable of binding phosphatidylinositol $(4,5)$ $\mathrm{P} 2$, therefore independently initiating signaling via Rac1, protein kinase $\mathrm{C} \alpha$, PI3K, Cdc42, mTORC2, and Akt (Ilan et al., 1998; Simons and Horowitz, 2001; Tkachenko et al., 2004; Partovian et al., 2008). Previous reports have also demonstrated that the uptake of angiogenic molecules such as bFGF, which requires astroglia to mediate neuroprotection in vitro, is mediated via syndecan 4 , the in vivo expression of which appears to be restricted to glial lineages (Knusel et al., 1990; Engele and Bohn, 1991; Hou et al., 1997; Hsueh and Sheng, 1999; Tkachenko et al., 2004). We therefore investigated whether angiogenin endocytosis was mediated by syndecan 4 .

By confocal microscopy, we observed that astrocytes express syndecan 4 under control conditions, which upon rhAng treatment, redistributed to colocalize with angiogenin-positive vesicles (Fig. 9A). To confirm this observation in a second approach, we used the in situ PLA (Söderberg et al., 2006). This assay detects 
A

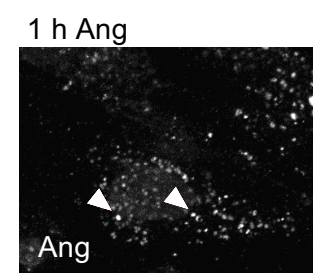

B

Ang

aAng aSyn4

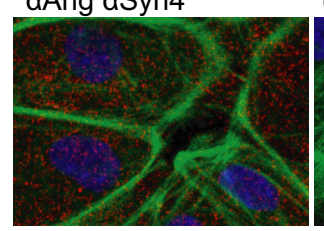

D

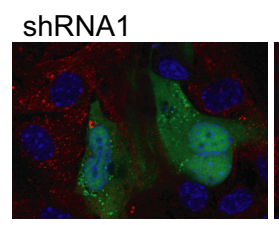

F

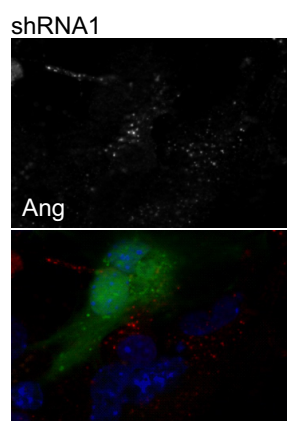

Scramble

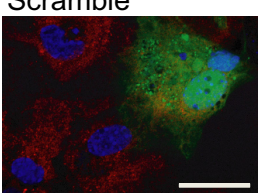

Syn4 GFP DAPI

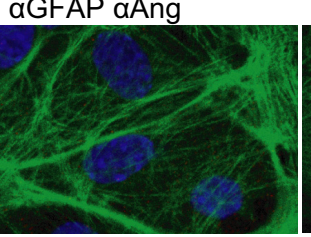

o Ang aAng aSyn4

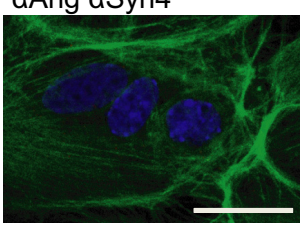

PLA Phalloidin DAPI no Ang

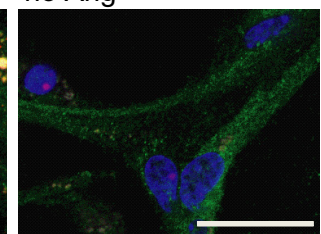

Ang Syn4 DAPI

C

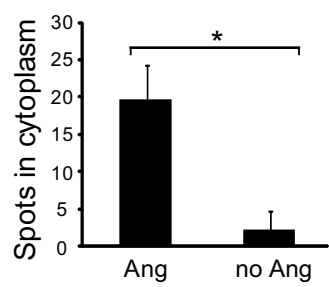

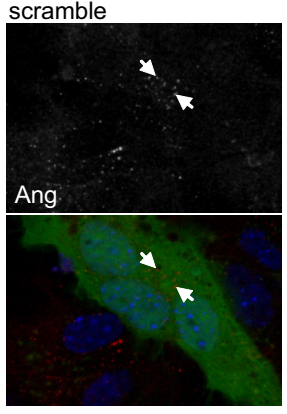
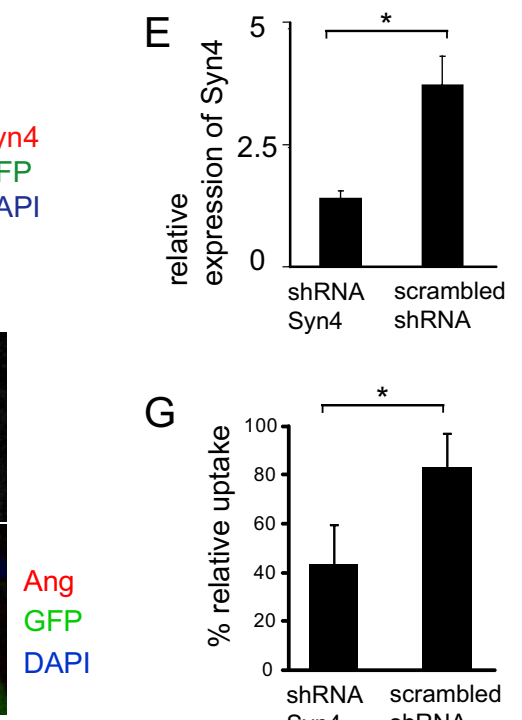

G

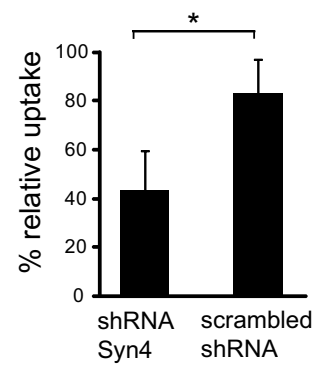

$\mathrm{H}$

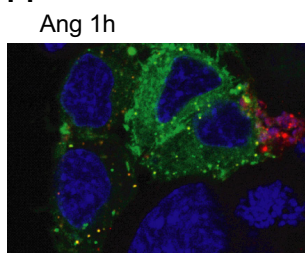
no Ang

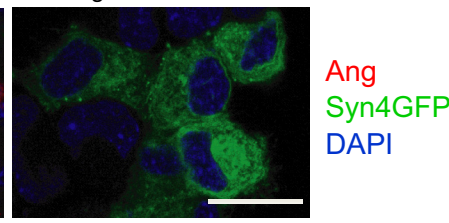

Figure 9. Internalization of rhAng by primary astrocytes depends on syndecan 4 as a receptor. $A$, Confocal images showing angiogenin ( $1 \mu \mathrm{g} / \mathrm{ml} ; 1 \mathrm{~h}$; red) colocalization with syndecan 4 (Syn4; green) staining in primary astrocyte cultures. Experiment was performed in triplicate with similar results, arrowheads indicate colocalization of angiogenin and syndecan 4 . $\boldsymbol{B}$, Confocal images showing PLA of rhAng-treated $(1 \mu \mathrm{g} / \mathrm{ml} ; 1 \mathrm{~h}$ ) primary astrocytes with anti-angiogenin ( $\alpha$ Ang) and anti-syndecan $4(\alpha$ Syn 4$)$ or anti-GFAP ( $\alpha$ GFAP) primary antibodies (phalloidin staining to visualize cell borders), quantification by blob-finder software $\left(\boldsymbol{C},{ }^{*} p \leq 0.05\right.$; mean $\pm S D ; n>350$ cells in three independent experiments). $\boldsymbol{D}$. Confocal images of primary astrocytes transfected with syndecan 4 shRNA or scrambled shRNA (transfected cells indicated by GFP fluorescence) and costained with syndecan 4 (red). $E$, Quantification of shRNA transfection efficiency ( $p<0.0005, t$ test; $n=45$ and 56 cells, respectively). $\boldsymbol{F}$, Confocal images of syndecan 4 shRNA- and scrambled shRNA-transfected ( $24 \mathrm{~h}$; green) astrocytes treated with rhAng and costained for angiogenin ( $1 \mu \mathrm{g} / \mathrm{ml}$; $1 \mathrm{~h}$; red; performed in duplicate with similar results, arrows indicate angiogenin-containing vesicles). G, Quantification of rhAng internalization ( $1 \mu \mathrm{g} / \mathrm{ml} ; 1 \mathrm{~h}$; red) by primary astrocytes after shRNA transfection ( $48 \mathrm{~h},{ }^{*} p \leq 0.05 ;$ mean \pm SD; $n=3$ experiments). $\boldsymbol{H}$, NSC34 cells overexpressing syndecan 4 (green) can uptake angiogenin (red; performed in duplicate with similar results). Scale bars, $25 \mu \mathrm{m}$.

interactions of proteins in fixed cells, and gives more information about the exact localization of the interaction partners. Figure $9 B$ illustrates that fixed, angiogenin-treated astrocytes showed many points of interaction between syndecan 4 and angiogenin (reported as red spots). There was little background by unspecific antibody interaction as shown by using an antibody against GFAP in combination with the angiogenin antibody (Fig. 9B). Quantification of this interaction using blob-finder software (see Materials and Methods) showed that significantly more spots were detectable in the angiogenin-treated versus vehicle-treated astrocytes (Fig. 9C). 
To prove that syndecan 4 was essential for rhAng uptake in astroglial cells, we used shRNA technology to silence syndecan 4 expression. Due to limited transfection efficiency in primary astroglia, it was not possible to quantify the inhibition of syndecan 4 expression by Western blotting. Instead, confocal microscopy was used to analyze syndecan 4 immunofluorescence in cells coexpressing GFP (Fig. 9D). Figure 9E provides a quantitative analysis of the most efficient shRNA vector tested that targeted syndecan 4. Analysis of GFP-expressing cells showed that transfection with this shRNA reduced angiogenin uptake by $48 \%$ compared with scrambled shRNA transfected controls (Fig. 9F, $G$ ).

Finally, we tested whether expression of syndecan 4 was sufficient to mediate rhAng uptake into NSC34 cells. Figure $9 H$ shows that NSC34 cells expressing GFP-syndecan 4 showed a vesicular uptake of angiogenin, similar to that observed in rhAng-treated astrocytes, whereas untransfected cells showed little detectable angiogenin uptake. As an additional negative control, GFP expression did not mediate angiogenin uptake in NSC34 cells (data not shown). Thus, syndecan 4 appeared to be necessary and sufficient to mediate angiogenin endocytosis.

\section{Discussion}

Through our investigations, we have elucidated a comprehensive mechanism of angiogenin signaling within cells of the spinal cord. We have highlighted a novel endogenous angiogenin signaling pathway between motoneurons and astroglia. Our studies indicate that angiogenin is a neuronally derived protein which constitutively and inducibly modifies the RNA profile of astroglia in paracrine. Importantly, we provide substantial evidence that the endogenous receptor for angiogenin in cells of spinal cord origin is syndecan 4, expressed exclusively by astroglia.

Motoneurons are polytrophic and show protection mediated by a variety of angiogenic growth factors, such as VEGF and FGF, via the expression of high-affinity receptors such as flk1, flt 1 , and FGFR1 (Gonzalez et al., 1995; Sendtner et al., 2000; Lambrechts and Carmeliet, 2006; Poesen et al., 2008). Most neurons require signaling endosomes to ensure sufficient prosurvival signaling reaches the nucleus (Howe and Mobley, 2005). In support of previously published data (Greenway et al., 2006), we found that motoneurons endogenously express angiogenin. However, we could find no evidence of uptake or endocytosis of exogenously applied angiogenin by motoneurons through immunocytochemistry or using fluorescently labeled rhAng. We also used a functional RNase readout in NSC34 cells; however, we failed to detect any RNA cleavage in response to exogenous angiogenin, despite robust activity in astroglia.

We found that motoneuronal NSC34 cells secrete both endogenous angiogenin and overexpressed angiogenin in a BFAsensitive manner (Rosa et al., 1992). By immunocytochemistry we showed that angiogenin overexpressed in NSC34 cells localizes to a tunicamycin-sensitive perinuclear reticulate structure and Golgi function-dependent granular structures before secretion. This ER-Golgi trafficking is consistent with the angiogenin protein sequence, which contains a hydrophobic amino acid-rich signal peptide, strongly predicted to couple translation with ER translocation and secretion (Kurachi et al., 1985; Barash et al., 2002). Our data support previous studies showing similar perinuclear/ER localization of endogenous angiogenin and also suggest a regulated release of angiogenin protein by secretory granule exocytosis (Kurachi et al., 1985; Pavlov et al., 2003). This mechanism of secretory granule packaging and regulated release is known for other angiogenic factors such as VEGF and FGF-2, which regulate stimulus-dependent angiogenesis by platelets
(Ribatti et al., 2001; Italiano et al., 2008). Thus, we believe that neurons constitutively express angiogenin and traffic the protein into secretory granules for both constitutive and stress-induced secretion.

We found RNA processing to present a robust readout for angiogenin activity in paracrine. We proved that angiogenin secreted from NSC34 cells mediates RNA cleavage in cells of astrocyte origin in paracrine (Fig. $5 A, D, G$ ). Interestingly, the RNA fragments in astrocytes migrated at a different size to that observed when expressed within NSC34 cells and to what is expected for the reported tRNA cleavage products (Fig. 5C,E) (Yamasaki et al., 2009). The paracrine RNA fragments showed a consistent size in all three models tested: endogenous NSC34 to mouse astroglia, overexpressed NSC34 angiogenin to human astrocytoma, and endogenously within mixed primary motoneuron cultures. Our data do not exclude a biological function of intraneuronal tRNA cleavage by angiogenin. Angiogenin has also been shown to have direct neurotrophic activities in the development of motoneurons, including axon pathfinding (Subramanian and Feng, 2007; Wu et al., 2007). However, our results rather suggest that angiogenin exerts important additional biological functions by acting in paracrine, and that angiogenin regulates astroglia function by targeting novel subsets of RNAs. Future studies will need to identify and characterize these novel angiogenin RNA substrates.

To gain further insight into the mechanism of angiogenin neuroprotection and its endogenous role in the spinal cord, we also delineated the mechanism of angiogenin uptake in astroglia. Similar to the endocytosis pathway for a variety of extracellular ligands, we found angiogenin uptake to be consistent with heparan sulfate proteoglycan-assisted CME (Belting, 2003; Dreyfuss et al., 2009). It has been shown previously that angiogenin binds heparin and cell surface proteoglycans (Soncin et al., 1994, 1997). However, we have shown that excess heparin can compete with the angiogenin receptor on astrocytes and prevent its uptake and concomitant paracrine RNA cleavage. We also showed that the endocytic mechanism for astroglial angiogenin uptake is CME, requiring dynamin-mediated vesicle budding, again by both immunocytochemistry and using RNase activity as a functional readout. Moreover, we have now defined syndecan 4 as a bona fide receptor for angiogenin, based on a variety of experimental approaches. With angiogenin uptake colocalized with syndecan 4 in cytosolic astroglial endosomes, and using the in situ proximity ligation assay, we could prove that the two proteins are positioned within close proximity $(<40 \mathrm{~nm})$ of each other. We further showed that syndecan 4 gene silencing inhibits angiogenin uptake in astrocyte cultures, thereby proving it to be necessary for astroglial angiogenin endocytosis. Finally, we showed that syndecan 4 overexpression is sufficient to reconstitute angiogenin endocytosis in cells that do not show significant basal angiogenin uptake or express detectable levels of endogenous syndecan 4 . Thus, we conclude that angiogenin interacts specifically with astroglial syndecan 4, which is both necessary and sufficient for its uptake. This finding suggests an explanation for the cell typespecific uptake of angiogenin in mixed primary motoneuron cultures, since the in vivo expression of syndecan 4 is restricted to astroglia (Hsueh and Sheng, 1999).

Astroglia may, however, not be the sole cell type responding to motoneuron-derived angiogenin. Syndecan 4 is also expressed by endothelial cells wherein it regulates multiple aspects of angiogenesis including ligand endocytosis (e.g., FGF-2 and VEGF) and stimulates endothelial migration and tubularization (Tkachenko et al., 2004, 2006; Nunes et al., 2008). This raises the possibility 
that motoneuron-derived angiogenin may stimulate endothelial cells to induce neovascularization. Moreover, astrocytes directly contact $9>9 \%$ of the endothelial basement membrane, where they regulate microvasculature blood flow (Iadecola and Nedergaard, 2007). Astroglia may use angiogenin to transmit intercellular signals to endothelial cells or may mediate angiogenin transcytosis to the endothelial membrane.

Together, our results provide new biological insights into the regulation of RNA metabolism in neurons and astrocytes and the role of angiogenin in this process. Moreover, our results also raise the prospect that angiogenin therapy may prove efficacious in human ALS patients.

\section{References}

Barash S, Wang W, Shi Y (2002) Human secretory signal peptide description by hidden Markov model and generation of a strong artificial signal peptide for secreted protein expression. Biochem Biophys Res Commun 294:835-842.

Belting M (2003) Heparan sulfate proteoglycan as a plasma membrane carrier. Trends Biochem Sci 28:145-151.

Brewer GJ, Torricelli JR, Evege EK, Price PJ (1993) Optimized survival of hippocampal neurons in B27-supplemented Neurobasal, a new serumfree medium combination. J Neurosci Res 35:567-576.

Burgoyne RD, Morgan A (2003) Secretory granule exocytosis. Physiol Rev 83:581-632.

Camu W, Henderson CE (1992) Purification of embryonic rat motoneurons by panning on a monoclonal antibody to the low-affinity NGF receptor. J Neurosci Methods 44:59-70.

Cashman NR, Durham HD, Blusztajn JK, Oda K, Tabira T, Shaw IT, Dahrouge S, Antel JP (1992) Neuroblastoma x spinal cord (NSC) hybrid cell lines resemble developing motor neurons. Dev Dyn 194:209-221.

Clement AM, Nguyen MD, Roberts EA, Garcia ML, Boillée S, Rule M, McMahon AP, Doucette W, Siwek D, Ferrante RJ, Brown RH Jr, Julien JP, Goldstein LS, Cleveland DW (2003) Wild-type nonneuronal cells extend survival of SOD1 mutant motor neurons in ALS mice. Science 302:113-117.

Crabtree B, Thiyagarajan N, Prior SH, Wilson P, Iyer S, Ferns T, Shapiro R, Brew K, Subramanian V, Acharya KR (2007) Characterization of human angiogenin variants implicated in amyotrophic lateral sclerosis. Biochemistry 46:11810-11818.

Damke H, Baba T, Warnock DE, Schmid SL (1994) Induction of mutant dynamin specifically blocks endocytic coated vesicle formation. J Cell Biol 127:915-934.

Daukas G, Zigmond SH (1985) Inhibition of receptor-mediated but not fluid-phase endocytosis in polymorphonuclear leukocytes. J Cell Biol 101:1673-1679.

Di Giorgio FP, Carrasco MA, Siao MC, Maniatis T, Eggan K (2007) Non-cell autonomous effect of glia on motor neurons in an embryonic stem cellbased ALS model. Nat Neurosci 10:608-614.

Doherty GJ, McMahon HT (2009) Mechanisms of endocytosis. Annu Rev Biochem 78:857-902.

Dreyfuss JL, Regatieri CV, Jarrouge TR, Cavalheiro RP, Sampaio LO, Nader HB (2009) Heparan sulfate proteoglycans: structure, protein interactions and cell signaling. An Acad Bras Cienc 81:409-429.

Eckert R, Ragg H (2003) Zinc ions promote the interaction between heparin and heparin cofactor II. FEBS Lett 541:121-125.

Engel T, Caballero-Caballero A, Schindler CK, Plesnila N, Strasser A, Prehn $\mathrm{JH}$, Henshall DC (2010) BH3-only protein Bid is dispensable for seizure-induced neuronal death and the associated nuclear accumulation of apoptosis-inducing factor. J Neurochem 115:92-101.

Engele J, Bohn MC (1991) The neurotrophic effects of fibroblast growth factors on dopaminergic neurons in vitro are mediated by mesencephalic glia. J Neurosci 11:3070-3078.

Fett JW, Strydom DJ, Lobb RR, Alderman EM, Bethune JL, Riordan JF, Vallee BL (1985) Isolation and characterization of angiogenin, an angiogenic protein from human carcinoma cells. Biochemistry 24:5480-5486.

Fu H, Feng J, Liu Q, Sun F, Tie Y, Zhu J, Xing R, Sun Z, Zheng X (2009) Stress induces tRNA cleavage by angiogenin in mammalian cells. FEBS Lett 583:437-442.

Gong YH, Parsadanian AS, Andreeva A, Snider WD, Elliott JL (2000) Restricted expression of $\mathrm{G} 86 \mathrm{R} \mathrm{Cu} / \mathrm{Zn}$ superoxide dismutase in astrocytes results in astrocytosis but does not cause motoneuron degeneration. J Neurosci 20:660-665.

Gonzalez AM, Berry M, Maher PA, Logan A, Baird A (1995) A comprehensive analysis of the distribution of FGF-2 and FGFR1 in the rat brain. Brain Res 701:201-226.

Greenway MJ, Andersen PM, Russ C, Ennis S, Cashman S, Donaghy C, Patterson V, Swingler R, Kieran D, Prehn J, Morrison KE, Green A, Acharya KR, Brown RH Jr, Hardiman O (2006) ANG mutations segregate with familial and 'sporadic' amyotrophic lateral sclerosis. Nat Genet 38:411-413.

Gurney ME, Pu H, Chiu AY, Dal Canto MC, Polchow CY, Alexander DD, Caliendo J, Hentati A, Kwon YW, Deng HX (1994) Motor neuron degeneration in mice that express a human $\mathrm{Cu}, \mathrm{Zn}$ superoxide dismutase mutation. Science 264:1772-1775.

Gutiérrez-Ortega A, Sánchez-Hernández C, Gómez-García B (2008) Respiratory syncytial virus glycoproteins uptake occurs through clathrinmediated endocytosis in a human epithelial cell line. Virol J 5:127.

Hetschko H, Voss V, Horn S, Seifert V, Prehn JH, Kögel D (2008) Pharmacological inhibition of Bcl-2 family members reactivates TRAIL-induced apoptosis in malignant glioma. J Neurooncol 86:265-272.

Heuser JE, Anderson RG (1989) Hypertonic media inhibit receptormediated endocytosis by blocking clathrin-coated pit formation. J Cell Biol 108:389-400.

Hou JG, Cohen G, Mytilineou C (1997) Basic fibroblast growth factor stimulation of glial cells protects dopamine neurons from 6-hydroxydopamine toxicity: involvement of the glutathione system. J Neurochem 69:76-83.

Howe CL, Mobley WC (2005) Long-distance retrograde neurotrophic signaling. Curr Opin Neurobiol 15:40-48.

Hsueh YP, Sheng M (1999) Regulated expression and subcellular localization of syndecan heparan sulfate proteoglycans and the syndecan-binding protein CASK/LIN-2 during rat brain development. J Neurosci 19:7415-7425.

Iadecola C, Nedergaard M (2007) Glial regulation of the cerebral microvasculature. Nat Neurosci 10:1369-1376.

Ilan N, Mahooti S, Madri JA (1998) Distinct signal transduction pathways are utilized during the tube formation and survival phases of in vitro angiogenesis. J Cell Sci 111:3621-3631.

Italiano JE Jr, Richardson JL, Patel-Hett S, Battinelli E, Zaslavsky A, Short S, Ryeom S, Folkman J, Klement GL (2008) Angiogenesis is regulated by a novel mechanism: pro- and antiangiogenic proteins are organized into separate platelet alpha granules and differentially released. Blood 111:1227-1233.

Jiang M, Chen G (2009) $\mathrm{Ca}^{2+}$ regulation of dynamin-independent endocytosis in cortical astrocytes. J Neurosci 29:8063-8074.

Kieran D, Sebastia J, Greenway MJ, King MA, Connaughton D, Concannon CG, Fenner B, Hardiman O, Prehn JH (2008) Control of motoneuron survival by angiogenin. J Neurosci 28:14056-14061.

Kirkpatrick CA, Selleck SB (2007) Heparan sulfate proteoglycans at a glance. J Cell Sci 120:1829-1832.

Knusel B, Michel PP, Schwaber JS, Hefti F (1990) Selective and nonselective stimulation of central cholinergic and dopaminergic development in vitro by nerve growth factor, basic fibroblast growth factor, epidermal growth factor, insulin and the insulin-like growth factors I and II. J Neurosci 10:558-570.

Kurachi K, Davie EW, Strydom DJ, Riordan JF, Vallee BL (1985) Sequence of the cDNA and gene for angiogenin, a human angiogenesis factor. Biochemistry 24:5494-5499.

Lafon-Cazal M, Adjali O, Galéotti N, Poncet J, Jouin P, Homburger V, Bockaert J, Marin P (2003) Proteomic analysis of astrocytic secretion in the mouse. Comparison with the cerebrospinal fluid proteome. J Biol Chem 278:24438-24448.

Lambrechts D, Carmeliet P (2006) VEGF at the neurovascular interface: therapeutic implications for motor neuron disease. Biochim Biophys Acta 1762:1109-1121.

Leland PA, Staniszewski KE, Park C, Kelemen BR, Raines RT (2002) The ribonucleolytic activity of angiogenin. Biochemistry 41:1343-1350.

Macia E, Ehrlich M, Massol R, Boucrot E, Brunner C, Kirchhausen T (2006) Dynasore, a cell-permeable inhibitor of dynamin. Dev Cell 10:839-850.

Moroianu J, Riordan JF (1994) Nuclear translocation of angiogenin in proliferating endothelial cells is essential to its angiogenic activity. Proc Natl Acad Sci U S A 91:1677-1681.

Nagai M, Re DB, Nagata T, Chalazonitis A, Jessell TM, Wichterle H, Przed- 
borski S (2007) Astrocytes expressing ALS-linked mutated SOD1 release factors selectively toxic to motor neurons. Nat Neurosci 10:615-622.

Nunes SS, Outeiro-Bernstein MA, Juliano L, Vardiero F, Nader HB, Woods A, Legrand C, Morandi V (2008) Syndecan-4 contributes to endothelial tubulogenesis through interactions with two motifs inside the proangiogenic N-terminal domain of thrombospondin-1. J Cell Physiol 214:828-837.

Ohsawa Y, Zhang G, Kametaka S, Shibata M, Koike M, Waguri S, Uchiyama Y (2003) Purification, cDNA cloning, and secretory properties of FLRG protein from PC12 cells and the distribution of FLRG mRNA and protein in rat tissues. Arch Histol Cytol 66:367-381.

Partovian C, Ju R, Zhuang ZW, Martin KA, Simons M (2008) Syndecan-4 regulates subcellular localization of mTOR Complex 2 and Akt activation in a PKCalpha-dependent manner in endothelial cells. Mol Cell $32: 140-149$

Pavlov N, Hatzi E, Bassaglia Y, Frendo JL, Evain Brion D, Badet J (2003) Angiogenin distribution in human term placenta, and expression by cultured trophoblastic cells. Angiogenesis 6:317-330.

Poesen K, Lambrechts D, Van Damme P, Dhondt J, Bender F, Frank N, Bogaert E, Claes B, Heylen L, Verheyen A, Raes K, Tjwa M, Eriksson U, Shibuya M, Nuydens R, Van Den Bosch L, Meert T, D’Hooge R, Sendtner M, Robberecht W, et al. (2008) Novel role for vascular endothelial growth factor (VEGF) receptor-1 and its ligand VEGF-B in motor neuron degeneration. J Neurosci 28:10451-10459.

Pramatarova A, Laganière J, Roussel J, Brisebois K, Rouleau GA (2001) Neuron-specific expression of mutant superoxide dismutase 1 in transgenic mice does not lead to motor impairment. J Neurosci 21:3369-3374.

Raoul C, Estévez AG, Nishimune H, Cleveland DW, deLapeyrière O, Henderson CE, Haase G, Pettmann B (2002) Motoneuron death triggered by a specific pathway downstream of Fas. potentiation by ALS-linked SOD1 mutations. Neuron 35:1067-1083.

Ribatti D, Crivellato E, Candussio L, Nico B, Vacca A, Roncali L, Dammacco F (2001) Mast cells and their secretory granules are angiogenic in the chick embryo chorioallantoic membrane. Clin Exp Allergy 31:602-608.

Roghani M, Moscatelli D (1992) Basic fibroblast growth factor is internalized through both receptor-mediated and heparan sulfate-mediated mechanisms. J Biol Chem 267:22156-22162.

Rosa P, Barr FA, Stinchcombe JC, Binacchi C, Huttner WB (1992) Brefeldin A inhibits the formation of constitutive secretory vesicles and immature secretory granules from the trans-Golgi network. Eur J Cell Biol 59:265-274.

Rosen DR, Siddique T, Patterson D, Figlewicz DA, Sapp P, Hentati A, Donaldson D, Goto J, O'Regan JP, Deng HX (1993) Mutations in Cu/Zn superoxide dismutase gene are associated with familial amyotrophic lateral sclerosis. Nature 362:59-62.

Sebastià J, Kieran D, Breen B, King MA, Netteland DF, Joyce D, Fitzpatrick SF, Taylor CT, Prehn JH (2009) Angiogenin protects motoneurons against hypoxic injury. Cell Death Differ 16:1238-1247.

Sendtner M, Pei G, Beck M, Schweizer U, Wiese S (2000) Developmental motoneuron cell death and neurotrophic factors. Cell Tissue Res 301:71-84.

Shapiro R, Vallee BL (1989) Site-directed mutagenesis of histidine-13 and histidine-114 of human angiogenin. Alanine derivatives inhibit angiogenininduced angiogenesis. Biochemistry 28:7401-7408.

Shapiro R, Riordan JF, Vallee BL (1986) Characteristic ribonucleolytic activity of human angiogenin. Biochemistry 25:3527-3532.

Shapiro R, Fox EA, Riordan JF (1989) Role of lysines in human angiogenin: chemical modification and site-directed mutagenesis. Biochemistry $28: 1726-1732$.

Simons M, Horowitz A (2001) Syndecan-4-mediated signalling. Cell Signal 13:855-862.

Söderberg O, Gullberg M, Jarvius M, Ridderstråle K, Leuchowius KJ, Jarvius J, Wester K, Hydbring P, Bahram F, Larsson LG, Landegren U (2006) Direct observation of individual endogenous protein complexes in situ by proximity ligation. Nat Methods 3:995-1000.

Soncin F, Shapiro R, Fett JW (1994) A cell-surface proteoglycan mediates human adenocarcinoma HT-29 cell adhesion to human angiogenin. J Biol Chem 269:8999-9005.

Soncin F, Strydom DJ, Shapiro R (1997) Interaction of heparin with human angiogenin. J Biol Chem 272:9818-9824.

St Clair DK, Rybak SM, Riordan JF, Vallee BL (1987) Angiogenin abolishes cell-free protein synthesis by specific ribonucleolytic inactivation of ribosomes. Proc Natl Acad Sci U S A 84:8330-8334.

Subramanian V, Feng Y (2007) A new role for angiogenin in neurite growth and pathfinding: implications for amyotrophic lateral sclerosis. Hum Mol Genet 16:1445-1453.

Tkachenko E, Lutgens E, Stan RV, Simons M (2004) Fibroblast growth factor 2 endocytosis in endothelial cells proceed via syndecan-4-dependent activation of Racl and a Cdc42-dependent macropinocytic pathway. J Cell Sci 117:3189-3199.

Tkachenko E, Elfenbein A, Tirziu D, Simons M (2006) Syndecan-4 clustering induces cell migration in a PDZ-dependent manner. Circ Res 98:1398-1404.

Tu H, Hsuchou H, Kastin AJ, Wu X, Pan W (2010) Unique leptin trafficking by a tailless receptor. FASEB J 24:2281-2291.

Turner BJ, Atkin JD, Farg MA, Zang DW, Rembach A, Lopes EC, Patch JD, Hill AF, Cheema SS (2005) Impaired extracellular secretion of mutant superoxide dismutase 1 associates with neurotoxicity in familial amyotrophic lateral sclerosis. J Neurosci 25:108-117.

Vercauteren D, Vandenbroucke RE, Jones AT, Rejman J, Demeester J, De Smedt SC, Sanders NN, Braeckmans K (2010) The use of inhibitors to study endocytic pathways of gene carriers: optimization and pitfalls. Mol Ther 18:561-569.

Wu D, Yu W, Kishikawa H, Folkerth RD, Iafrate AJ, Shen Y, Xin W, Sims K, Hu GF (2007) Angiogenin loss-of-function mutations in amyotrophic lateral sclerosis. Ann Neurol 62:609-617.

Yamanaka K, Chun SJ, Boillee S, Fujimori-Tonou N, Yamashita H, Gutmann DH, Takahashi R, Misawa H, Cleveland DW (2008) Astrocytes as determinants of disease progression in inherited amyotrophic lateral sclerosis. Nat Neurosci 11:251-253.

Yamasaki S, Ivanov P, Hu GF, Anderson P (2009) Angiogenin cleaves tRNA and promotes stress-induced translational repression. J Cell Biol 185: $35-42$. 